Marquette University

e-Publications@Marquette

\title{
Measuring the Plasticity of Social Approach: A Randomized Controlled Trial of the Effects of the PEERS Intervention on EEG Asymmetry in Adolescents with Autism Spectrum Disorders
}

\author{
Amy V. Van Hecke \\ Marquette University, amy.vanhecke@marquette.edu \\ Sheryl Jayne Stevens \\ Marquette University, sheryl.stevens@marquette.edu \\ Audrey M. Carson \\ Marquette University \\ Jeffrey S. Karst \\ Marquette University, jeffrey.karst@marquette.edu \\ Bridget Dolan \\ Marquette University, bridget.dolan@marquette.edu
}

See next page for additional authors

Follow this and additional works at: https://epublications.marquette.edu/psych_fac

Part of the Psychology Commons

\section{Recommended Citation}

Van Hecke, Amy V.; Stevens, Sheryl Jayne; Carson, Audrey M.; Karst, Jeffrey S.; Dolan, Bridget; Schohl, Kirsten A.; McKindles, Ryan J.; Remmel, Rheanna; and Brockman, Scott, "Measuring the Plasticity of Social Approach: A Randomized Controlled Trial of the Effects of the PEERS Intervention on EEG Asymmetry in Adolescents with Autism Spectrum Disorders" (2015). Psychology Faculty Research and Publications. 230.

https://epublications.marquette.edu/psych_fac/230 


\section{Authors}

Amy V. Van Hecke, Sheryl Jayne Stevens, Audrey M. Carson, Jeffrey S. Karst, Bridget Dolan, Kirsten A. Schohl, Ryan J. McKindles, Rheanna Remmel, and Scott Brockman 


\title{
Measuring the Plasticity of Social Approach: A Randomized Controlled Trial of the Effects of the PEERS Intervention on EEG Asymmetry in Adolescents with Autism Spectrum Disorders
}

\author{
Amy Vaughan Van Hecke \\ Department of Psychology, Marquette University \\ Milwaukee, WI \\ Sheryl Stevens \\ Department of Psychology, Marquette University \\ Milwaukee, WI \\ Audrey M. Carson \\ Department of Psychology, Marquette University \\ Milwaukee, WI \\ Jeffrey S. Karst \\ Department of Psychology, Marquette University \\ Milwaukee, WI \\ Bridget Dolan \\ Department of Psychology, Marquette University \\ Milwaukee, WI
}

Journal of Autism and Developmental Disorders, Vol 45, No. 2 (February 2015): pg. 316-335. DOI. This article is @ Springer and permission has been granted for this version to appear in e-Publications@Marquette. Springer does not grant permission for this article to be further copied/distributed or hosted elsewhere without the express permission from Springer. 
NOT THE PUBLISHED VERSION; this is the author's final, peer-reviewed manuscript. The published version may be accessed by following the link in the citation at the bottom of the page.

\author{
Kirsten Schohl \\ Department of Psychology, Marquette University \\ Milwaukee, WI \\ Ryan J. McKindles \\ Department of Biomedical Engineering, \\ Marquette University, \\ Milwaukee, WI \\ Rheanna Remmel \\ Department of Psychology, Marquette University \\ Milwaukee, WI \\ Scott Brockman \\ Department of Psychology, Marquette University \\ Milwaukee, WI
}

\begin{abstract}
This study examined whether the Program for the Education and Enrichment of Relational Skills (PEERS: Social skills for teenagers with developmental and autism spectrum disorders: The PEERS treatment manual, Routledge, New York, 2010a) affected neural function, via EEG asymmetry, in a randomized controlled trial of adolescents with Autism spectrum disorders (ASD) and a group of typically developing adolescents. Adolescents with ASD in PEERS shifted from right-hemisphere gamma-band EEG asymmetry before PEERS to left-hemisphere EEG asymmetry after PEERS, versus a waitlist ASD group. Left-hemisphere EEG asymmetry was associated with more social contacts and knowledge, and fewer symptoms of autism. Adolescents with ASD in PEERS no longer differed from typically developing adolescents in leftdominant EEG asymmetry at post-test. These findings are discussed via the Modifier Model of Autism (Mundy et al. in Res Pract Persons Severe Disabl 32(2):124, 2007), with emphasis on remediating isolation/withdrawal in ASD. Keywords: Autism, Adolescence, EEG, Asymmetry, PEERS, Intervention, Brain, Plasticity
\end{abstract}

\title{
Introduction
}

Autism spectrum disorders (ASD) are a group of pervasive developmental disorders with effects on language, social functioning, and behavior (APA 2000). Symptoms in ASD are not static, but may change form across developmental periods, with the transition to

Journal of Autism and Developmental Disorders, Vol 45, No. 2 (February 2015): pg. 316-335. DOI. This article is @ Springer and permission has been granted for this version to appear in e-Publications@Marquette. Springer does not grant permission for this article to be further copied/distributed or hosted elsewhere without the express permission from Springer. 
adolescence being one of the most dramatic (Anderson et al. 2011; Shea and Mesibov 2005; Thurm et al. 2011). Most theorists agree that a neurological disturbance in activity and connectivity contributes to the social deficits in ASD (see Dawson 2008; Minshew and Keller 2010; Mundy 2003, and Neuhaus, et al. 2010, for reviews). In addition, high rates of depression and withdrawal in ASD (Lopata et al. 2010; Stewart et al. 2006; Whitehouse et al. 2009) make it possible that increasingly severe manifestations of ASD are characterized by relatively greater right-frontal hemisphere neural activity and relatively less left-frontal hemisphere activity (Burnette et al. 2011; Moncrieff 2010). However, it is still unknown whether these neural patterns can predictably be affected by experience or interventions for ASD in dynamic developmental periods. To our knowledge, no previous study has examined whether effective behavioral interventions for adolescents with ASD affect neural function. Within this manuscript, behavioral and cortical development in adolescence, the implications of neural asymmetry, and validated interventions for this developmental period are first reviewed. Then, the current study, which examines whether electrophysiological asymmetry in adolescents with ASD changes due to a Randomized Controlled Trial (RCT) of an empirically supported relationship-development intervention, is presented.

\section{Behavioral and Cortical Development in Adolescence}

Increased self-consciousness and importance of peer relationships are behavioral hallmarks of adolescence (Steinberg and Morris 2001). The shift from reliance on sympathetic parents and adults to less-forgiving peers is particularly difficult for adolescents with ASD, whose social understanding and skills generally are not as developed as their peers without ASD (Tantam 2003). Adolescents with ASD may be rejected, bullied, marginalized, and isolated (Symes and Humphrey 2010; Tse et al. 2007), and they experience strong feelings of loneliness (Bauminger and Kasari 2000; Lasgaard et al. 2010; White and Roberson-Nay 2009; Whitehouse et al. 2009). Adolescents with high-functioning ASD may know that they are different, but not know why or how to change (Tantam 2003). As a result, a significant number of adolescents with ASD are at-risk for a cascade of secondary psychopathology, including depression, anxiety, 
NOT THE PUBLISHED VERSION; this is the author's final, peer-reviewed manuscript. The published version may be accessed by following the link in the citation at the bottom of the page.

and suicidality (Eussen et al. 2012; Ghaziuddin and Zafar 2008; Stewart et al. 2006; Tantam 2003; White and Roberson-Nay 2009).

At the same time, dramatic changes in neurophysiology occur in adolescence, which may reflect a critical experience-expectant period. Conventional wisdom has assumed that the bulk of important brain development occurred in infancy and toddlerhood. However, recent work in neuroimaging (see Blakemore 2008; Luciana 2010, and Marsh et al. 2008, for reviews) has found a growth spurt of cortical gray matter, particularly in the frontal lobe, in late childhood (Giedd et al. 1999; Gogtay and Thompson 2010). Gray matter then tends to decrease from puberty through adulthood, perhaps indicating continued pruning of synapses (Gogtay et al. 2004; Huttenlocher and de Courten 1987; Sowell et al. 1999). In addition, connective white matter tracts within and between the hemispheres continue to develop (Barnea-Goraly et al. 2005; Giedd et al. 1999; Gogtay et al. 2004; Paus 2010; Schmithorst and Yuan 2010) and myelinate in adolescence (Paus 2010; Yakovlev and Lecours 1967).

These dramatic developments in neural structure and function may be affected by the social environment available at or before this developmental stage (Makinodan et al. 2012; Sheridan et al. 2012). A multitude of studies have established that social isolation and loneliness are a significant determinant of physical health and longevity (Cacioppo and Hawkley 2009; Holt-Lunstad et al. 2010; Uchino et al. 1996), and mental health in humans (see Hawkley and Cacioppo 2010; Heinrich and Gullone 2006, for reviews). Interestingly, the experience of "social pain" activates the same neural circuits as physical pain (Kross et al. 2011). Individuals that perceive themselves as isolated and lonely show weaker prefrontal and ventral striatal reward system responses to pleasant pictures of people, less activation in perspective-taking areas of temporo-parietal cortex (Cacioppo et al. 2009), and more maladaptive cardiovascular responses to threatening or negative stimuli (Ong et al. 2012). Research has also shown that children who experience isolation early in development show significantly smaller gray matter and white matter volumes as adolescents (Mehta et al. 2009), and that isolation in post-weaned animals reduces myelination of white matter tracts (Makinodan et al. 2012) and reduces prefrontal cortical volume (Fone and Porkess 2008). Although these studies of isolation do not perfectly mirror the and permission has been granted for this version to appear in e-Publications@Marquette. Springer does not grant permission for this article to be further copied/distributed or hosted elsewhere without the express permission from Springer. 
experiences of children and adolescents with ASD, it is likely that the pervasive lack of social orienting and approach (Greene et al. 2011; Mundy $\underline{1995}$ ) and positive social interactions (Whitehouse et al. 2009) throughout development, which characterize ASD, may have similar deleterious effects on experience-expectant neural development.

\section{Hemispheric Asymmetry: Individual Differences and Links with Outcomes}

An additional factor to consider, when examining links between social experiences and neural patterns, is that individual differences in the relative dominance of one hemisphere over the other have been linked to certain psychological styles (Tomarken et al. 1992). Specifically, multiple studies (Davidson et al. 1990; Davidson 1998; Sutton and Davidson 1997) have found that individuals who exhibit higher relative left-hemisphere dominance are characterized as higher in approach motivation and positive affective style, and that this characteristic may be protective against stress in at-risk children (Lopez-Duran et al. 2012). In contrast, individuals who exhibit higher relative right-hemisphere dominance are characterized by withdrawal, negative emotional style, and poorer outcomes (Fox et al. 2001; Miskovic et al. 2010; Mitchell and Pössel 2011; Smith and Bell 2010). Although most studies have found these differences to pertain mainly to asymmetry of frontal cortical activity, two studies also found similar results at more temporal/central cortical locations (Davidson et al. 1990; Sutton and Davidson 1997). These approach-orientation differences (Gray and McNaughton 2000) have been noted in infants (Fox 1991, 1994), children (Baving et al. 2002), and adults (Sutton and Davidson 1997).

In ASD, studies have shown a negative effect on skills/tasks lateralized to the left hemisphere (Dawson et al. 1982, 1986; Dawson 1983; Dawson and Fernald 1987; Gunter et al. 2002; Rinehart et al. 2002; Sabbagh 1999; Shamay-Tsoory et al. 2010); and an unexpected right hemisphere advantage on certain tasks (Ashwin et al. 2005). Neurologically, research has demonstrated decreases in activity (Dawson et al. 1995; Stroganova et al. 2007) and blood flow (Chiron et al. 1995) in the left hemisphere; significantly increased activity in the right frontal and temporal lobes, versus controls 
(Kleinhans et al. 2008); a lack of expected leftward structural asymmetry in gray and white matter, versus controls (Haznedar et al. 2006; Lo et al. 2011; Wan et al. 2012); and an abnormal enlargement of the right hemisphere (Herbert et al. 2005), all perhaps suggesting hyper-activation of the right hemisphere and hypo-activation of the left hemisphere in ASD (Shamay-Tsoory et al. 2010). These differences have been noted more readily in areas of the brain where white matter mylenates later in development (Herbert et al. 2004, 2005), and have been linked to social skills and approach in ASD (Kylliäinen et al. 2012; Sutton et al. 2005), suggesting a potential important impact of experience/environment on this progression of atypicality. Lastly, parents' retrospective reports of first concerns about autism were earlier in children with ASD with more rightdominant asymmetry versus children with ASD with a more leftdominant profile (Burnette et al. 2011).

Given these findings, recent research and theory has begun to explore whether individual differences in asymmetry domains might be malleable due to experience (Boles et al. 2008; Güntürkün and Manns 2010; Steinmetz et al. 1995), and have observed increases in leftfrontal asymmetry due to treatment or intervention (Davidson et al. 2003; Moscovitch et al. 2011). However, to our knowledge, no study has addressed whether asymmetry in ASD is responsive to intervention, although research has noted that approach tendencies in infants and toddlers with ASD may moderate the effects of early behavioral intervention (Beglinger and Smith 2005; Sherer and Schreibman 2005).

\section{Behavioral Intervention for Adolescents with ASD}

Given the numerous behavioral and neurophysiological challenges in adolescence in ASD, a number of social skills intervention programs have been designed for this age group (although most focus on somewhat younger children: see Reichow et al. 2013; White et al. 2007, for a review). These programs report some success in teaching social skills (Cotter 1997, as cited in White et al. 2007), emotion recognition (Barnhill et al. 2002; Solomon et al. 2004), and perspective-taking (Ozonoff and Miller 1995). However, the majority of programs report null findings for generalization and flexible use of the 
skills outside of the group, in the naturalistic setting (White et al. 2007).

One new social skills treatment directly addresses the problems with generalization of skills into naturalistic settings. The Program for the Education and Enrichment of Relational Skills (PEERS: Laugeson and Frankel 2010a, b) specifically targets friendships, relationship development, and remediation of isolation in adolescents with ASD. Social rules of adolescent etiquette are specifically targeted, and are based upon Children's Friendship Training (Frankel and Myatt 2003), which has been shown to be effective in ASD (Frankel and Myatt 2007). The first PEERS study found that adolescents who completed PEERS exhibited increased knowledge of how to make and keep friends, increased hosted get-togethers, better quality of friendships, and better overall social skills (Laugeson et al. 2009). Additionally, recent work has found that these treatment gains are maintained 14 weeks later (Laugeson et al. 2012). Thus, it appears that this promising program does show evidence of ameliorating both the isolation and social skills deficits inherent in ASD in adolescence.

\section{Summary}

Designing studies that can measure neurological change in response to therapy has come to the forefront as an important goal for psychological science, in general (Banaschewski and Brandeis 2007; Davidson 2012; Davidson and McEwen 2012; Gabbard 2000), and autism research, specifically (McPartland and Pelphrey 2012). Two published studies (Bolte et al. 2006; Faja et al. 2012) have measured short-term brain activity changes after adults with autism completed social training programs. Even though these interventions were brief and conducted with adults, the studies found that brain activity changed in response to the social training. A recent study found increased EEG activity to faces in a group of young children with autism who had been enrolled in early, intensive intervention (Dawson et al. 2012). Another study found increased efficiency of brainstem responses to sound after children with ASD completed an auditory intervention (Russo et al. 2010). Lastly, a correlational study found that white matter integrity in children with autism was linked with onset and duration of early intervention (Pardini et al. 2012). Thus, 
the idea that intervention may affect neurophysiology and electrophysiology has been borne out in adults and children with ASD.

Importantly, however, research has not addressed this question during adolescence in ASD, a period of neural plasticity (Greenough and Black 1992; Black et al. 1998), whereupon adult "wiring" and capabilities are established (for a review, see Marsh et al. 2008; Nelson 2000). Recent work has also emphasized the importance of addressing loneliness and social support in at-risk populations, and the potential effects remediating these domains could have on neural function (Davidson and McEwen 2012; Uchino et al. 1996). However, to date, no social skills or friendship development program targeting adolescents with ASD has assessed whether effects on the brain are apparent in adolescents who show positive behavioral responses to the intervention, or whose social environments are enriched as a result of the intervention.

Therefore, the current study examined whether remediation of friendship skills and social isolation, via an empirically-supported, Randomized Controlled Trial (RCT), relationship-development intervention (PEERS: Laugeson et al. 2009, 2012), affected neural activity in adolescents with ASD. The central hypothesis of this study examined whether a shift to left-hemisphere dominant EEG spectral asymmetry would be evident in adolescents with autism who experienced social benefit from the PEERS intervention. The first and primary aim of this study was to examine whether neural asymmetry would differentially change in adolescents with ASD who participated in an RCT of the PEERS relationship-development program. The second aim of this study was to examine relations between asymmetry and social approach behavior: specifically, whether neural asymmetry was related to symptoms of autism, amount of social contacts, or acquisition of intervention concepts by the adolescents with ASD. The third and final aim was to examine neural asymmetry in context: to compare neural asymmetry in adolescents with ASD who did and did not complete PEERS to neural asymmetry in a sample of healthy, typically developing adolescents without ASD. 
NOT THE PUBLISHED VERSION; this is the author's final, peer-reviewed manuscript. The published version may be accessed by following the link in the citation at the bottom of the page.

\section{Method}

\section{Participants}

A total of 110 families were recruited for this longitudinal, randomized controlled trial (RCT) study (see Fig. 1). Participants were recruited from local intervention agencies, autism support groups, an in-house waiting list for PEERS treatment, and community advertisements over a period of 2 years. Prior to the first appointment, families of adolescents with ASD were randomly assigned to either the Experimental (EXP; $n=41$ ) or Waitlist Control (WL; $n=38$ ) group. EXP families completed the first appointment and entered a PEERS group immediately, after which they completed a follow-up appointment. WL families completed the first appointment, did not enter PEERS, and completed a follow-up appointment approximately 13 weeks later. WL families then entered the next available PEERS group, no more than 14 weeks later. PEERS group sizes were maintained at 10 or fewer adolescents, and consisted entirely of either EXP or WL families (i.e., EXP families did not participate in intervention groups containing WL families). PEERS was provided to families of adolescents with ASD free of charge in either a fall (August-December) or spring (January-May) session. Adolescents recruited for inclusion as part of the typically developing (TYP; $n=31$ ) comparison group were seen on only one occasion and were not provided with PEERS treatment. 
NOT THE PUBLISHED VERSION; this is the author's final, peer-reviewed manuscript. The published version may be accessed by following the link in the citation at the bottom of the page.

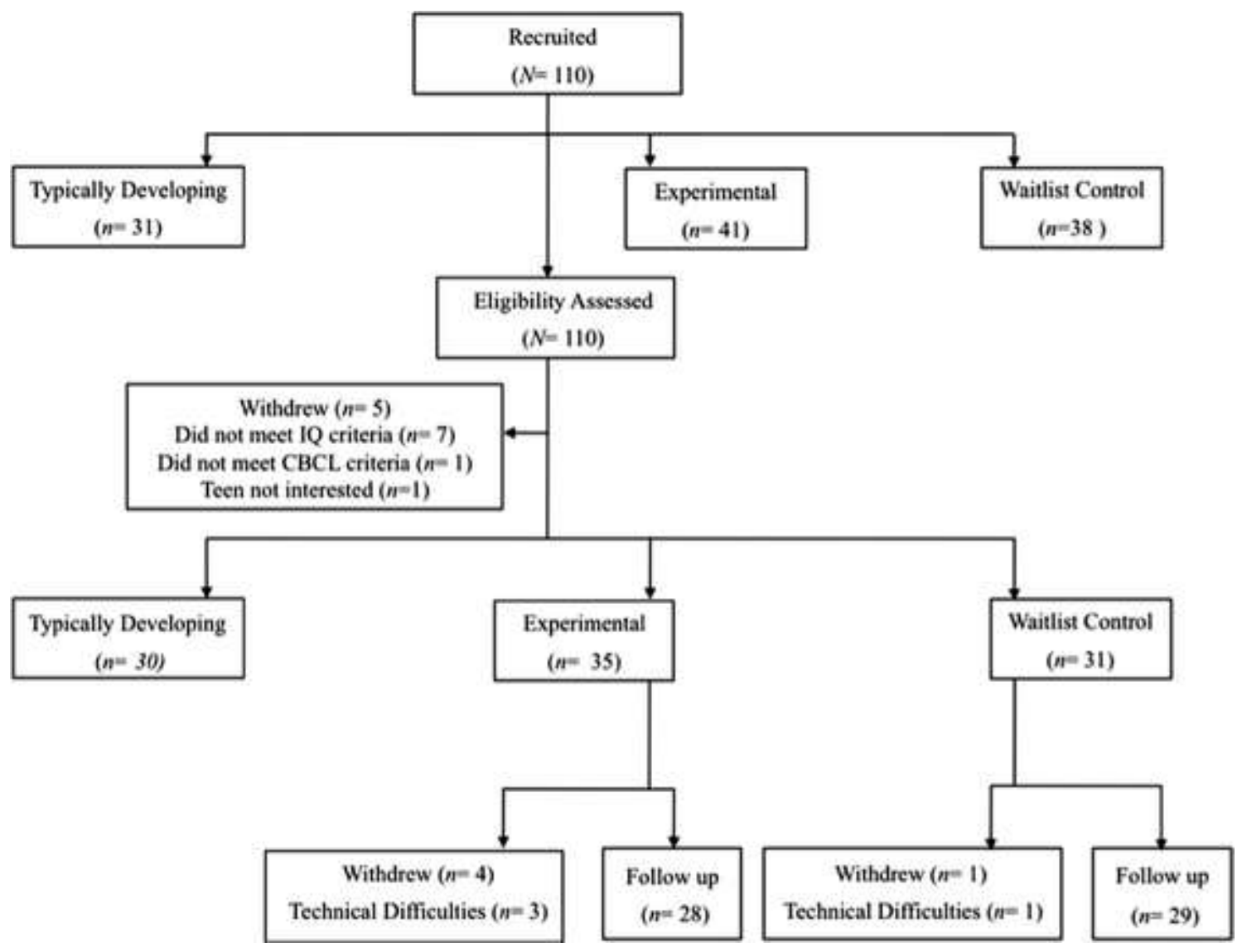

Fig. 1. CONSORT recruitment diagram

Inclusion criteria for adolescents with ASD consisted of the following: (a) adolescent was between 11 years of age and 16 years of age at intake, (b) adolescent had both verbal and full scale IQ of 70 or greater on the Kaufman Brief Intelligence Test Second Edition (KBIT-2: Kaufman and Kaufman 2005), (c) adolescent and caregiver spoke English fluently, (d) adolescent did not have neural, physical, hearing, or visual impairment that prohibited participation in a class setting, (e) adolescent did not have comorbid bipolar disorder or schizophrenia, (f) adolescent was enrolled in middle or high school, or adolescent was home-schooled but had weekly peer contact outside of family, (g) adolescent met autism or autism spectrum diagnosis on Module 3 or 4 of the Autism Diagnostic Observation Schedule-Generic (ADOS-G: Lord et al. 1999), (h) adolescent indicated interest in learning how to make friends, and (i) family attended at least 12 out of the 14 PEERS sessions. Inclusion criteria for typically developing adolescents (TYP) included $a-f$, as well as (1) scoring under 13 on the Autism Spectrum Screening Questionnaire (ASSQ: Ehlers et al. 1999), and (2) scoring

Journal of Autism and Developmental Disorders, Vol 45, No. 2 (February 2015): pg. 316-335. DOI. This article is (c) Springer and permission has been granted for this version to appear in e-Publications@Marquette. Springer does not grant permission for this article to be further copied/distributed or hosted elsewhere without the express permission from Springer. 
under a $t$ score of 65 on all scales of the Child Behavior Checklist (CBCL: Achenbach and Rescorla 2001). Of the 110 families recruited, 14 did not continue participation following assessment of eligibility at the first intake appointment. Specifically, 5 families withdrew at intake, 7 adolescents did not meet IQ criteria, 1 adolescent did not meet CBCL criteria, and 1 adolescent was not interested in learning how to make friends. 5 additional families withdrew from the study over the course of the intervention/waiting period, and follow-up data on 4 subjects was lost due to technical difficulties (see Fig. 1).

The final sample included 87 adolescents, relatively evenly distributed among the WL ASD $(n=29)$, EXP ASD $(n=28)$, and TYP ( $n=30)$ groups. Racial backgrounds included $93.1 \%$ Caucasian, $3.4 \%$ African-American, $1.1 \%$ Asian-American, $1.1 \%$ biracial and $1.1 \%$ unspecified. $83.9 \%$ of participants were male, and $81.6 \%$ were right handed. The average participant age was 13.6 years $(S D=1.5)$. All subjects demonstrated an IQ of 70 or higher, with an average IQ of 103 (SD = 15.1) as assessed on the KBIT-2. Confirmatory diagnostic evaluation of adolescents with ASD on the ADOS-G indicated a mean communication score of 3.47 ( $S D=1.58$ ), social score of 7.60 (SD = 2.09), and total score of $11.05(S D=3.31)$. With regard to concurrent pharmacological intervention, all adolescents in the TYP group were un-medicated. Of those in the WL ASD and EXP ASD groups, $31.58 \%$ of participants were un-medicated during experimentation, $28.07 \%$ were receiving one medication, $22.81 \%$ two medications, $15.79 \%$ three or more medications, and $1.75 \%$ declined to report medication status. Among subjects receiving medications, $65.79 \%$ were receiving antidepressants, $57.89 \%$ stimulant medications, $15.79 \%$ atypical antipsychotics, $13.16 \%$ alpha-2a receptor agonists, $10.53 \%$ mood stabilizers, $10.53 \%$ selective norepinephrine reuptake inhibitors, and $26.32 \%$ other medications. No adolescents received additional psychological therapies for anxiety or depression at or between the research collection sessions. See Table $\underline{1}$ for data on parental age, education, and income. No significant differences on demographic variables were noted between the EXP, WL, and TYP groups. 
Table 1. Sample demographic characteristics

Characteristic

Age (years)
IQ (points)
ADOS total score
Communication score
Social score
Mother's age (years)
Father's age (years)
Gender (percentage)
Male

Female

Handedness (percentage)

Right

Left

Race (percentage)

Asian

African-American

Biracial

Caucasian

Unreported

Income (percentage)

Under $50 \mathrm{k}$

50-75 k

75-100 k

$100 \mathrm{k}$ plus

Unreported
EXP M(SD)

$14.1(1.3)$

$99.4(14.6)$

11.29 (3.5)

3.57 (1.8)

7.64 (2.0)

46.2 (5.0)

$47.3(5.0)$

78.6

21.4

82.1

14.3

0

3.6

0

92.9

3.6

14.3

32.1

14.3

35.7

3.6

Parent education (percentage)

High school

3.6

Vocational/technical

Some college

Junior college

B.A./B.S.

M.A./M.S.

Ph.D/M.D./J.D.

Unreported

\section{1}

14.3

3.6

50.0

17.9

3.6

0
WL M(SD)

13.3 (1.7)

$102.2(16.5)$

$10.83(3.2)$

3.38 (1.4)

7.55 (2.2)

45.1 (5.4)

$46.9(5.2)$

79.3

20.7

75.9

24.1

3.4

6.9

0

89.7

0

20.6

10.0

13.8

20.0

10.3

13.3

56.7

3.4

6.9

13.8

3.4

0

51.7

10.3

13.8

0
TYP M (SD)

13.3 (1.3)

107.1 (13.6)

$-$

$-$

$-$

$44.7(4.2)$

$47.1(4.4)$

93.3

6.7

86.7

10.0

0

3

96.7

0

EXP = Experimental ASD group, WL = waitlist control ASD group, TYP = typically developing group, $M=$ mean, $S D=$ standard deviation, IQ = Kaufman brief intelligence scale full-scale score, ADOS = autism diagnostic observation schedulegeneric 


\section{Procedure}

Families who expressed interest in the study by calling a number or writing to an email address, provided with an informational letter, were contacted by phone or email. Phone screening consisted of adolescent age confirmation, previous ASD (if any) and other diagnostic history, school history, initial assessment of the parent's understanding of the adolescent's motivation to participate (ASD only), English language criteria, and ability to attend weekly PEERS sessions (ASD only). If these criteria were met, a laboratory intake appointment was made. At this visit, written informed consent and assent were obtained, adolescent interest in learning how to make friends was confirmed via a structured interview with the adolescent (ASD only; Mental Status Checklist: Laugeson and Frankel 2010b), adolescent language skill, ASD diagnosis (if any), and IQ were confirmed, and research measures completed (see "Measures"). A \$30 incentive was given to adolescents upon PEERS completion or at conclusion of the intake visit, or if the adolescent was tested as part of the TYP group. Adolescents and families who did not meet study acceptance criteria were provided with compensation of $\$ 30$ to thank them for their time. Typically developing adolescents completed measures in one laboratory appointment and were not followed over time.

\section{Measures}

\section{Screening and Intake}

At the intake visit, caregivers were asked to complete a demographic questionnaire and a questionnaire concerning their adolescent's health and medication status. Adolescents with ASD were interviewed and an interest in learning how to make and keep friends was confirmed (Mental Status Checklist, Laugeson \& Frankel, 2010b). Diagnoses of adolescents with ASD were confirmed using the Autism Diagnostic Observation Schedule Modules 3 and 4 (ADOS-G: Lord et al. 1999). Typically developing adolescents were screened using the ASSQ (Ehlers et al. 1999) and the CBCL (Achenbach and Rescorla 2001), completed by a caregiver. Adolescents' cognitive abilities were 
NOT THE PUBLISHED VERSION; this is the author's final, peer-reviewed manuscript. The published version may be accessed by following the link in the citation at the bottom of the page.

assessed via the Kaufman Brief Intelligence Test-Second Edition (Kaufman and Kaufman 2005).

\section{Questionnaires}

Questionnaire measures were utilized to index behavioral change in adolescent autism symptoms, social contacts, and PEERS knowledge concepts. Caregivers completed the Social Responsiveness Scale (SRS: Constantino 2005), which provides global and specific ratings of characteristics of autism. The SRS yields a Total score where a higher score indicates more impairment or more symptoms of autism. The SRS has good established internal validity and reliability (Constantino et al. 2003). In addition, Cronbach's alpha reliability, computed from data in this study, was .84 for the Total score. Caregivers also completed the Quality of Socialization QuestionnaireRevised (QSQ-R: Laugeson et al. 2012). This caregiver-completed questionnaire measures number and quality of the adolescent's gettogethers with peers. Two items from the QSQ-R were used for the current study: (1) the number of peer get-togethers the adolescent had initiated and participated in over the prior month, and (2) the number of peer get-togethers the adolescent had been invited to and participated in over the prior month. These two items were summed to create a new variable indicative of total social contact the adolescent had experienced over the last month, QSQ-R Contact. Lastly, adolescents completed the Test of Adolescent Social Skills Knowledge (TASSK: Laugeson et al. 2012). The TASSK was developed to measure acquisition and maintenance of the concepts and skills taught in PEERS. Twenty-two items covering all sessions were presented in a multiple choice and true/false format. A Total score reflecting knowledge of PEERS concepts was calculated. Thus, scores on the TASSK at pre-test reflected a baseline measurement of adolescents' social skills and knowledge. Given the range of topics and lack of subscales on this questionnaire, Cronbach's reliability alpha was not computed for the TASSK.

\section{Electroencephalogram Session}

Caregivers and adolescents were then escorted to the electroencephalogram laboratory and the adolescent was asked to sit in a comfortable chair facing a 19-inch computer monitor located 
approximately three feet away. The caregiver was seated in an adjoining room, out of the adolescent's line of vision. An appropriately sized 64-channel electrode net (Electrical Geodesics, Inc., Eugene, OR) was then positioned according to standard procedures on the adolescent's head, and adjusted so that all impedances were at or below $40 \mathrm{kOhm}$. Continuous resting EEG was amplified and sampled at $1,000 \mathrm{~Hz}$, using a Netamps 300 (Electrical Geodesics, Inc., Eugene, OR) for a total of $3 \mathrm{~min}$. During the recording session, the adolescent was asked to focus on a fixation point displayed on a black computer background. Adolescents were monitored for alertness and attention to the fixation point, and were videotaped during EEG collection to provide a record of potential movement artifact.

ASD Intervention (Program for the Education and Enrichment of Relational Skills, PEERS: Laugeson and Frankel 2010a, $\underline{b}$; Laugeson et al. 2009, 2012)

PEERS is a short-term, outpatient, empirically supported, manualized intervention that was designed to address the development and maintenance of friendships in adolescents with ASD (see Laugeson et al. 2012, for details). The first author was certified in providing PEERS, and trained graduate students in a clinical psychology Ph.D. program to assist with and co-lead the PEERS adolescent and caregiver groups. Undergraduate students served as coaches/assistants for the PEERS groups. All adolescent group leaders had at least a Master's degree in psychology and had extensive experience in ASD.

The PEERS intervention consists of 14 , weekly, $1.5 \mathrm{~h}$-long, small group sessions (Laugeson et al. 2012) (see Table 2). Parent groups are conducted separately but concurrently with adolescent groups so that parents support skill practice and maintenance outside of the group. Five overarching areas are addressed by the intervention: (1) developing conversation skills, (2) expanding social networks, (3) learning peer etiquette and addressing a negative reputation, (4) increasing get-togethers, and (5) handling bullying, teasing, and conflicts with peers (see Table 2). Each week, the previous week's topic/skills are reviewed and experiences with homework discussed. Then, the new skill/topic/didactic is introduced and its relevance for 
adolescents with ASD is concretely explained. Group leaders then perform role-plays and adolescents rehearse the skill/topic. Feedback is given, and homework is then assigned. Fidelity checks and procedures were conducted for all sessions and for all groups, via undergraduate coaches following the manual during the session and ensuring no topics were missed. The final, 14th session consisted of a brief, final didactic review, a graduation ceremony, and a party for the adolescents and their families, where prizes were distributed to the adolescents.

Table 2. PEERS sessions, associated didactic, and link to social approach

Session Didactic Skill/topic related to social approach

1

2 Conversational skills II: two-way conversations

3 Conversational skills III: electronic communication

$4 \quad$ Choosing appropriate friends

5

6
Peer entry II: exiting a conversation Get-togethers

Peer entry I: entering a conversation

Appropriate use of humor
1. Ask another person a question

2. Answer your question

3. Find common interests

4. Share the conversation

1. Ask open-ended and follow-up questions

2. Listen to your friend

3. Make eye contact

1. Make phone calls

2. Contact friends via text, email, or internet

1. Find and approach groups of adolescents that have similar interests

2. Enroll in new extra-curricular activity with other adolescents

1. Pay attention to people's responses to your use of humor

1. Watch and listen to a group before approaching

2. Move closer to the group

3. Show interest in the group

4. Make periodic eye contact

5. Join the group by making a comment

6. Evaluate group's receptiveness

1. Check group members for signs of social interest

1. Greet your guest

2. Invite them in

3. Introduce your guest to others

4. Offer your guest a beverage/snack and a tour

5. Ask your guest what they want to do

6. Praise and compliment your guest

7. Walk your guest to the door and thank them for coming

8. Tell guest "goodbye and see you later"

1. Praise your friend

2. Share and take turns

3. At the end of the game say "good game"

Journal of Autism and Developmental Disorders, Vol 45, No. 2 (February 2015): pg. 316-335. DOI. This article is (c) Springer and permission has been granted for this version to appear in e-Publications@Marquette. Springer does not grant permission for this article to be further copied/distributed or hosted elsewhere without the express permission from Springer. 
NOT THE PUBLISHED VERSION; this is the author's final, peer-reviewed manuscript. The published version may be accessed by following the link in the citation at the bottom of the page.

\begin{tabular}{|c|c|c|}
\hline Session & Didactic & Skill/topic related to social approach \\
\hline 10 & $\begin{array}{l}\text { Rejection I: teasing and } \\
\text { embarrassing feedback }\end{array}$ & $\begin{array}{l}\text { 1. Rather than ignoring teasers, use verbal } \\
\text { comebacks to verbal teasing (e.g., "Whatever") }\end{array}$ \\
\hline 11 & $\begin{array}{l}\text { Rejection II: bullying and } \\
\text { bad reputations }\end{array}$ & $\begin{array}{l}\text { 1. Hang out with other people to avoid bullies } \\
\text { 2. Follow the crowd to correct a bad reputation } \\
\text { 3. Acknowledge your prior reputation } \\
\text { 4. Find a new crowd }\end{array}$ \\
\hline 12 & Handling disagreements & $\begin{array}{l}\text { 1. Listen to other person } \\
\text { 2. Repeat what they said } \\
\text { 3. Explain your side } \\
\text { 4. Apologize and try to solve the problem }\end{array}$ \\
\hline 13 & Rumors and gossip & $\begin{array}{l}\text { 1. Spread a rumor about yourself telling about } \\
\text { how the original rumor is not true }\end{array}$ \\
\hline 14 & $\begin{array}{l}\text { Graduation and } \\
\text { termination }\end{array}$ & $\begin{array}{l}\text { 1. Participate in a party with other teens in the } \\
\text { group: play games together and congratulate } \\
\text { each other on progress }\end{array}$ \\
\hline
\end{tabular}

Although all PEERS sessions are listed, only skills/topics presented in PEERS that may be related to social approach are listed here. Reproduced with permission of the authors

\section{Outtake Session}

The outtake session was completed just prior to the 14th PEERS session, for the EXP group, and approximately 14 weeks after intake for the WL group. ASD participants returned to the lab and repeated many of the same measures as at intake, including the SRS, QSQ-R, and TASSK questionnaires and the EEG session, conducted in the same manner as at intake. However, the ADOS, the Kaufman Brief Intelligence Test, the interview measure of teen interest, and the demographics and health/medications questionnaires were not repeated at the outtake.

\section{EEG Data Analysis}

Recorded EEG data was filtered from 0.3 to $100 \mathrm{~Hz}$ and exported from NetStation (Electrical Geodesics, Inc.: Eugene, OR) software, and custom MATLAB scripts (2012a, The MathWorks, Natick, MA) using EEGLAB functions (Delorme and Makeig 2004), were used for the remaining off-line analysis of the data. EEG data were rereferenced to a common average reference, which included the reference electrode. Low frequency noise and power line noise were band-pass filtered from 2 to $100 \mathrm{~Hz}$ and notch filtered from 59 to $61 \mathrm{~Hz}$ using an 8th order, Butterworth, zero-phase filter, respectively. Data were then epoched into one second periods and those with large

Journal of Autism and Developmental Disorders, Vol 45, No. 2 (February 2015): pg. 316-335. DOI. This article is (C) Springer and permission has been granted for this version to appear in e-Publications@Marquette. Springer does not grant permission for this article to be further copied/distributed or hosted elsewhere without the express permission from Springer. 
movement artifact were autorejected using the pop_autorej function (EEGLAB). In order to correct for additional artifacts, remaining epoched data were decomposed using an adaptive mixture independent component analysis (AMICA) (Palmer et al. 2008) and artifact components identified using ADJUST (Mognon et al. 2010) and visual inspection. Remaining data were used to calculate the average power spectral density using Welch's method (1024pt segments, $50 \%$ overlap) for each electrode. Additionally, spectral powers were calculated for the delta $(0-4 \mathrm{~Hz})$, theta $(4-8 \mathrm{~Hz})$, alpha $(8-12 \mathrm{~Hz})$, beta $(12-30 \mathrm{~Hz})$, and gamma $(30-50 \mathrm{~Hz})$ bands by calculating the area under the average spectrums. Power values were averaged across all electrodes for the left- and right-hemispheres, separately (see Fig. 2), within their respective frequency bands. Data were then natural-logarithm transformed to correct for violations of normality inherent in spectral power values. Asymmetry scores, for each band, at PRE and POST, were computed by subtracting the natural log power in the left-hemisphere from the right (Right In power-Left In power). Thus, positive asymmetry scores indicate relatively more righthemisphere activity, whereas negative asymmetry scores indicate relatively more left-hemisphere activity.

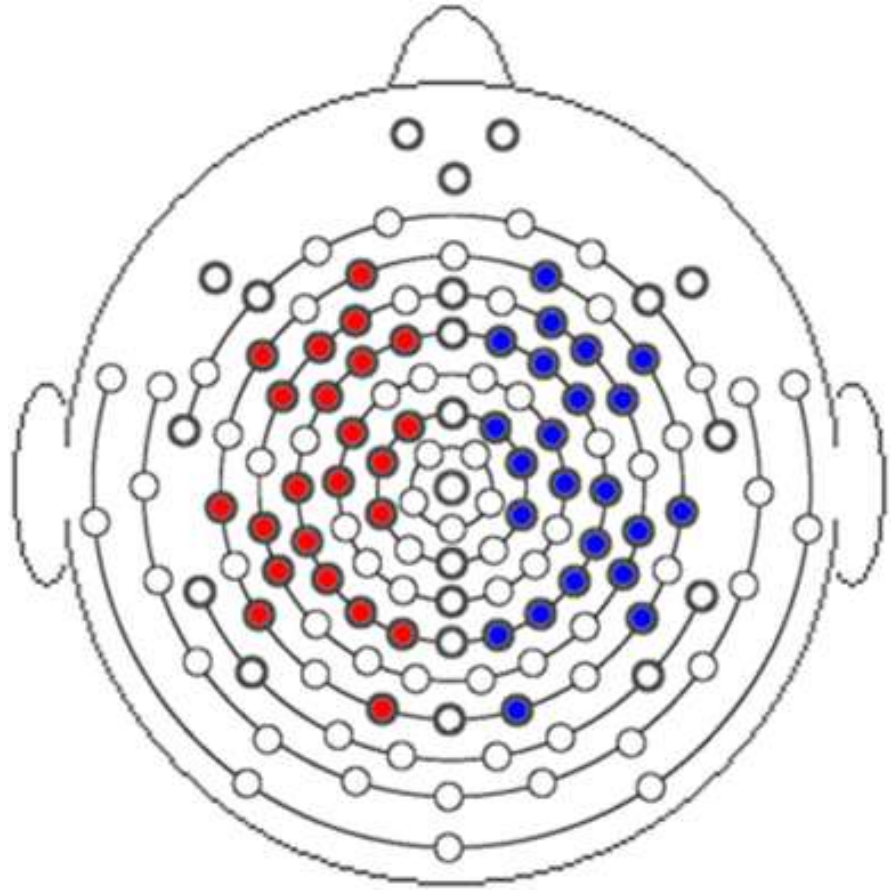

Fig. 2. Electrode layout. Note Red electrodes indicate left hemisphere; blue electrodes indicate right hemisphere. Data collected using Geodesic Sensor Net Hydrocell 64channel pediatric medium, large, adult small, and adult medium nets, based on standard sizing for head circumference (Electrical Geodesics: Eugene, OR) 
NOT THE PUBLISHED VERSION; this is the author's final, peer-reviewed manuscript. The published version may be accessed by following the link in the citation at the bottom of the page.

\section{Data Analytic Plan}

The first aim of this study was to examine whether spectral power asymmetry estimates changed differentially over time based on whether PEERS treatment was or was not received in the randomized controlled trial. To address this aim, a $2 \times 2 \times 5$ mixed model, repeated measures ANOVA was conducted. The between subjects variable, treatment group (GROUP), had two levels: experimental (EXP) and waitlist control (WL). The first within-subjects variable, time (TIME), had two levels: pre-test (PRE) and post-test (POST). The second within-subjects variable, frequency band (BAND), had five levels: delta, theta, alpha, beta, and gamma. The dependent variable was the natural logarithm of EEG spectral power asymmetry. The second aim of this study was to explore whether neural asymmetry was related to social behavior and knowledge as rated by parents and adolescents. First, three $2 \times 2$ mixed model, repeated measures ANOVAs were separately conducted, one for the caregiver-rated measure of autism symptoms, the SRS Total score, one for the caregiver-rated measure of adolescent social contact, the QSQ-R Contact score, and one for the adolescent-rated measure of PEERS knowledge, the TASSK. The between subjects variable, treatment group (GROUP), had two levels: experimental (EXP) and waitlist control (WL). The within-subjects variable, time (TIME), had two levels: pre-test (PRE) and post-test (POST). The dependent variable for each was the summary total score on the measure. Second, bivariate correlations for the Post-test EEG asymmetry and behavioral measures were calculated. The third aim of this study was to compare EEG asymmetry values between the two groups of adolescents with ASD and a comparison group of healthy adolescents who did not have ASD. Of particular interest was whether EEG asymmetry data from the EXP group was more similar to the WL group or the TYP group at pretest as compared to post-test. To address this aim, two $3 \times 5$ mixed model, repeated measures ANOVAs were conducted. The first ANOVA between subjects variable, treatment group (GROUP), had three levels: experimental at pre-test (EXP), waitlist control at pre-test (WL), and typically developing (TYP). The second within-subjects variable, frequency band (BAND), had five levels: delta, theta, alpha, beta, and gamma. The second ANOVA was similar, except that the between subjects variable, treatment group (GROUP), had three levels 
consisting of: experimental at post-test (EXP), waitlist control at posttest (WL), and typically developing (TYP). The dependent variable for both analyses was the natural logarithm of EEG spectral power asymmetry. Unless otherwise noted, all statistical tests were analyzed at $p<.05$ in SPSS 19.0 (IBM 2011).

\section{Results}

\section{Data Screening}

Descriptive statistics for spectral power asymmetry values at pre- and post-test (if applicable) for the EXP, WL, and TYP groups are presented in Table $\underline{3}$. Examination of distributions, separately by group, time, and in total, revealed no significant underlying problems with the assumptions of normality, homogeneity of variance, or outlying values in all measures, except for the QSQ-R. For this measure, five significant outliers were noted over the pre- and posttest QSQ-R Contact scores. These values were replaced with the next most extreme value in the distribution (Winsorization: Howell 2012). Violations of sphericity, and corrections applied, are noted below within each analysis. Lastly, a series of exploratory analyses were conducted to determine whether gender, left-handedness, or medication use unduly influenced results. Analyses (a) with and without female adolescents, (b) with and without left-handed adolescents, and (c) controlling for medication use, did not show any significant differences in results. Therefore, females and left-handed adolescents were retained, and medication use was not considered further, in order to preserve power.

Table 3. Descriptive statistics for EEG spectral power asymmetry values at pre- and post-test

$\begin{array}{llcllll}\begin{array}{c}\text { Frequency } \\ \text { band }\end{array} & \begin{array}{c}\text { EXP M } \\ \text { (SD) }\end{array} & \begin{array}{c}\text { Pre } \\ \text { WL } \\ \text { (SD) }\end{array} & \begin{array}{c}\text { TYP M } \\ \text { (SD) }\end{array} & \begin{array}{c}\text { EXP M } \\ \text { (SD) }\end{array} & \begin{array}{c}\text { Post } \\ \text { WL M } \\ \text { (SD) }\end{array} & \begin{array}{c}\text { TYP M } \\ \text { (SD) }\end{array} \\ \text { Delta } & .11(.69) & -.16 & .27(.63) & .29(.78) & -.09 & - \\ & & (.58) & & & (.51) & \\ \text { Theta } & .10(.46) & .07(.46) & .02(.39) & .18(.51) & -.16 & - \\ & & & & & (.45) & \\ \text { Alpha } & .29(.47) & .17(.42) & .10(.45) & .27(.46) & .25(.47) & - \\ \text { Beta } & -.64(.71) & -.68 & -1.31 & -.67(.92) & -.92 & - \\ & & (.74) & (.70) & & (.64) & \end{array}$


NOT THE PUBLISHED VERSION; this is the author's final, peer-reviewed manuscript. The published version may be accessed by following the link in the citation at the bottom of the page.

\begin{tabular}{|c|c|c|c|c|c|c|}
\hline \multirow{2}{*}{$\begin{array}{c}\text { Frequency } \\
\text { band }\end{array}$} & \multicolumn{3}{|c|}{ Pre } & \multicolumn{3}{|c|}{ Post } \\
\hline & $\begin{array}{l}\text { EXP M } \\
\text { (SD) }\end{array}$ & $\begin{array}{l}\text { WL M } \\
\text { (SD) }\end{array}$ & $\begin{array}{c}\text { TYP M } \\
\text { (SD) }\end{array}$ & $\begin{array}{l}\text { EXP M } \\
\text { (SD) }\end{array}$ & $\begin{array}{l}\text { WL M } \\
\text { (SD) }\end{array}$ & $\begin{array}{c}\text { TYP M } \\
\text { (SD) }\end{array}$ \\
\hline Gamma & $-.49(.89)$ & $\begin{array}{l}-.52 \\
(.89)\end{array}$ & $\begin{array}{l}-1.23 \\
(.85)\end{array}$ & $\begin{array}{l}-.85 \\
(1.04)\end{array}$ & $\begin{array}{l}-.48 \\
(.98)\end{array}$ & - \\
\hline
\end{tabular}

$\mathrm{EXP}=$ Experimental group, $\mathrm{WL}=$ waitlist group, $\mathrm{TYP}=$ typically developing group (measured on only one occasion), $\mathrm{M}=$ mean, $\mathrm{SD}=$ standard deviation, Pre $=$ asymmetry value at pre-test, Post $=$ asymmetry value at post-test. Asymmetry was calculated as Ln Right power-Ln Left power; therefore, positive values indicate relatively more right hemisphere activity and negative values indicate relatively more left hemisphere activity

\section{Aim 1: Changes in Neural Asymmetry in ASD}

The assumption of sphericity was violated for within-subjects factor BAND, Mauchley's $W(9)=.07, p<.05, \varepsilon=.43$, and BAND by TIME, Mauchley's $W(9)=.08, p<.05, \varepsilon=.59$. Therefore, all withinsubjects values cited are Hyunh-Feldt corrected. The main effect for the between subjects variable, GROUP, was not significant, $F$ ( 1 , $55)=1.30, p=.26$; $n s$. The main effect for the within subjects variable, TIME, was not significant, $F(1,55)=.76, p=.39$; $n s$. The main effect for the within subjects variable, BAND, was significant, $F$ $(1.72,94.74)=35.26, p<.05$, partial $\eta^{2}=.39$, observed power $=1.0$. The TIME by BAND interaction was significant, $F(2.34$, 128.93) $=2.99, p<.05$, partial $\eta^{2}=.05$, observed power $=.62$. The interaction GROUP by TIME was not significant, $F(1,55)=.13$, $p=.72$; ns. However, the interaction GROUP by TIME by BAND was significant, $F(4,220)=4.01, p<.05$; partial $\eta^{2}=.07$, observed power $=.91$.

Given these results, post hoc tests were conducted on the GROUP by TIME by BAND interaction. A Bonferroni corrected alpha level of .01 was used to adjust for multiple comparisons. Analysis of simple interaction effects, splitting the file by BAND, revealed that the three-way interaction of GROUP $x$ TIME $x$ BAND was not driven by the delta, theta, alpha, or beta bands (no significant main or interaction effects in these bands). However, significant effects emerged in the gamma band. Specifically, there was a significant GROUP $x$ TIME effect in gamma asymmetry, $F(1,220)=7.68, p<.01$. Follow-up paired $t$ tests, with a Bonferroni corrected alpha level of .025, indicated that the EXP group significantly increased in left-dominant gamma asymmetry over time, $t(27)=2.55, p<.025$ (PRE mean $=-.49$, 
POST mean $=-.85)$, whereas the WL group did not change in leftdominant gamma asymmetry over time, $t(28)=-.23, p=.82$, ns (PRE mean $=-.52$, POST mean $=-.48)$. Thus, these results suggest that the group that received PEERS showed relatively more lefthemisphere-dominant shift in gamma activity, whereas the group that did not receive PEERS did not show any changes in gamma asymmetry over the same time period.

\section{Aim 2: Relations Between Neural Asymmetry and Social Behavioral Change in ASD}

\section{Social Responsiveness Scale}

The main effect for the between subjects variable, GROUP, was significant, $F(1,52)=5.13, p<.05$; partial $\eta^{2}=.09$, observed power $=.60$. The main effect for the within subjects variable, TIME, was significant, $F(1,52)=42.42, p<.05$; partial $\eta^{2}=.45$, observed power $=1.0$. However, both of these effects were qualified by a significant interaction between TIME and GROUP, $F(1,52)=11.88$, $p<.05$; partial $\eta^{2}=.19$, observed power $=.92$. Post hoc paired $t$ tests, with a Bonferroni corrected alpha level of .025, splitting the file by GROUP, revealed that EXP SRS scores significantly decreased over time, $t(25)=5.76, p<.025$, PRE mean $=103.81$, POST mean $=80.85$. SRS scores in the WL group also decreased significantly over time, $t(27)=2.88, p<.025$, although the difference was smaller, PRE mean $=108.11$, POST mean $=101.04$. Thus, these results suggest that the ASD group that received PEERS showed a larger decrease in symptoms of autism as rated by their caregivers on the SRS over time, as compared to the waitlist control ASD group.

\section{Quality of Socialization Questionnaire-Revised}

The main effect for the between subjects variable, GROUP, was significant, $F(1,52)=4.62, p<.05$; partial $\eta^{2}=.08$, observed power $=.56$. The main effect for the within subjects variable, TIME, was significant, $F(1,52)=9.81, p<.05$; partial $\eta^{2}=.16$, observed power $=.87$. However, both of these were qualified by a significant interaction between TIME and GROUP, $F(1,52)=26.60, p<.05$; 
partial $\eta^{2}=.34$, observed power $=1.0$. Post hoc paired $t$ tests, with a Bonferroni corrected alpha level of .025, splitting the file by GROUP, revealed that EXP QSQ-R Contact scores significantly increased over time, $t(26)=-5.90, p<.025$, PRE mean $=1.03$, POST mean $=4.37$. In contrast, QSQ-R Contact scores in the WL group did not significantly change over time, $t(26)=1.42, p=.17, n s$, PRE mean $=1.96$, POST mean $=1.15$. Thus, these results suggest that the ASD group that received PEERS showed an increase in social contacts via hosted and invited get-togethers over time, whereas the ASD group that did not receive PEERS did not show a change in reported social contacts over time.

\section{Test of Adolescent Social Skills Knowledge}

The main effect for the between subjects variable, GROUP, was significant, $F(1,55)=26.93, p<.05$; partial $\eta^{2}=.33$, observed power $=.99$. The main effect for the within subjects variable, TIME, was significant, $F(1,55)=175.86, p<.05$; partial $\eta^{2}=.76$, observed power $=1.0$. However, both of these were qualified by a significant interaction between TIME and GROUP, $F(1,55)=126.33, p<.05$; partial $\eta^{2}=.70$, observed power $=1.0$. Post hoc paired $t$ tests, with a Bonferroni corrected alpha level of .025, splitting the file by GROUP, revealed that EXP TASSK scores significantly increased over time, $t$ $(27)=-15.62, p<.025$, PRE mean $=13.1$, POST mean $=21.46$. In contrast, TASSK scores in the WL group did not change over time, $t$ $(28)=-1.61, p=.12, n s$, PRE mean $=13.45$, POST mean $=14.14$. Thus, these results suggest that the ASD group that received PEERS showed an increase in knowledge of PEERS concepts, whereas the ASD group that did not receive PEERS did not show a change in knowledge of PEERS concepts over time.

\section{EEG and Behavioral Measures Correlations}

Measures were selected for inclusion in correlational analyses based on outcomes from Aim 1, in order to preserve power. There was a significant negative association between gamma asymmetry values

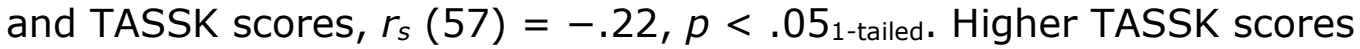
were related to lower gamma asymmetry values (i.e., more dominant left hemisphere asymmetry). There was also a significant negative correlation between gamma asymmetry and QSQ-R Contact scores, $r_{s}$ 


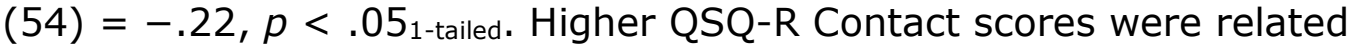
to lower gamma asymmetry values (i.e., more dominant left hemisphere asymmetry). There was also a significant positive correlation between left-dominant asymmetry and the SRS Total score,

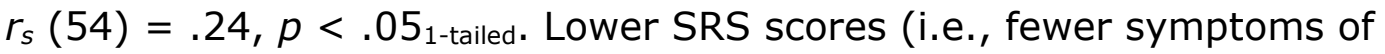
autism) were related to lower gamma asymmetry values (i.e., more dominant left hemisphere asymmetry). Therefore, adolescents with ASD who showed (1) greater PEERS knowledge, (2) more social contacts, and (3) fewer autism symptoms at post-test, also showed a greater degree of relative left-hemisphere dominant EEG activity in the gamma band.

\section{Aim 3: EEG Asymmetry Comparisons Between Adolescents with ASD and Typically Developing Adolescents}

The first analysis compared EEG asymmetry in the ASD groups prior to intervention to the typically developing control group. The assumption of sphericity was violated for within-subjects factor BAND, Mauchley's $W(9)=.10, p<.05, \varepsilon=.47$. Therefore, all withinsubjects values cited are Hyunh-Feldt corrected. The main effect for the between subjects variable, GROUP, was significant, $F(2$, $84)=4.28, p<.05$, partial $\eta^{2}=.09$, observed power $=.73$. The main effect for the within subjects variable, BAND, was significant, $F$ (1.86, $156.17)=71.44, p<.05$, partial $\eta^{2}=.46$, observed power $=1.0$. The GROUP by BAND interaction was significant, $F(3.72,156.17)=6.05$, $p<.05$, partial $\eta^{2}=.13$, observed power $=.98$. Given these results, post hoc tests were conducted on the GROUP by BAND interaction. A Bonferroni corrected alpha level of .01 was used to adjust for multiple comparisons. Analysis of simple main effects, utilizing five separate one-way ANOVAs (splitting the file by BAND), revealed that the interaction of GROUP $x$ BAND was not driven by group asymmetry differences at pre-test in the delta, theta, or alpha bands (no significant group differences in these bands). However, significant group differences at pre-test emerged in the beta, $F(2$, $156.17)=6.15, p<.01$, and gamma bands, $F(2,156.17)=7.66$, $p<.01$. Follow-up Tukey tests indicated that although the EXP and WL groups did not differ from each other, both the EXP and WL groups had significantly lower left-dominant beta asymmetry at pre-test than 
the TYP group (EXP PRE mean $=-.64$, WL PRE mean $=-.68$, TYP mean $=-1.31$ ). Similarly, although the EXP and WL groups did not differ from each other, both the EXP and WL groups had significantly lower left-dominant gamma asymmetry at pre-test than the TYP group $($ EXP PRE mean $=-.49, \mathrm{WL}$ PRE mean $=-.52$, TYP mean $=-1.23)$. Thus, these results suggest that, prior to PEERS, both ASD groups had neural asymmetry patterns that were characterized by less leftdominant asymmetry in beta and gamma bands versus a typically developing group of adolescents (see Fig. $\underline{3}$ ).

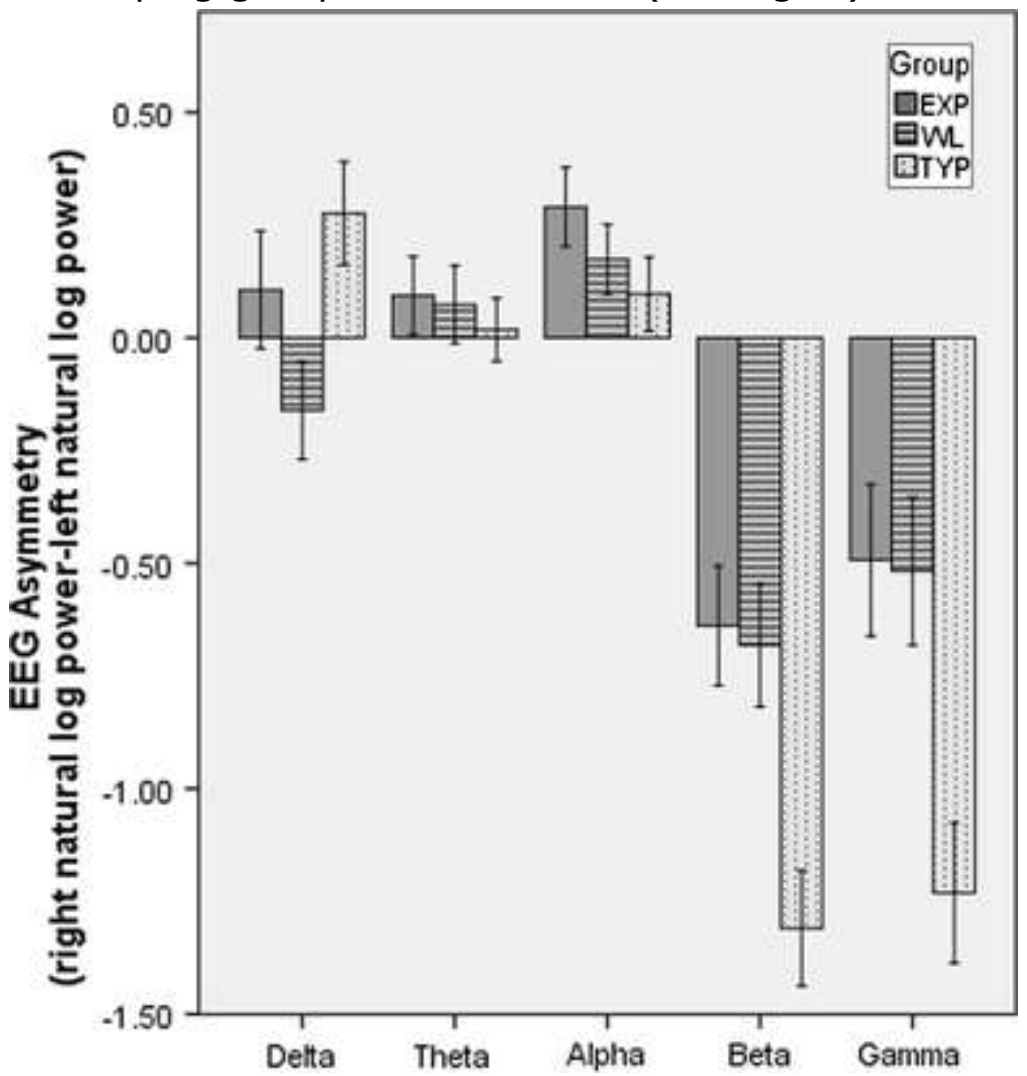

Fig. 3. EEG Asymmetry in Adolescents with ASD at Pre-test versus Typically Developing Adolescents. Note Values are mean EEG asymmetry at Pre-test by group, calculated as (natural log right hemisphere power) minus (natural log left hemisphere power). Thus, more negative values indicate relatively greater left hemisphere EEG power. EXP = adolescents with ASD who completed PEERS intervention between preand post-test measures; $\mathrm{WL}=$ adolescents with ASD who did not complete PEERS intervention between pre- and post-test measures; TYP = typically developing adolescents (measured on one occasion). Delta $(0-4 \mathrm{~Hz})$, Theta $(4-8 \mathrm{~Hz})$, Alpha (8$12 \mathrm{~Hz})$, Beta $(12-30 \mathrm{~Hz})$, and Gamma $(30-50 \mathrm{~Hz})$ EEG frequency bands are plotted on the $X$ axis

The second analysis compared the ASD groups at post-test to the typically developing group. The assumption of sphericity was

Journal of Autism and Developmental Disorders, Vol 45, No. 2 (February 2015): pg. 316-335. DOI. This article is (C) Springer and permission has been granted for this version to appear in e-Publications@Marquette. Springer does not grant permission for this article to be further copied/distributed or hosted elsewhere without the express permission from Springer. 
violated for within-subjects factor BAND, Mauchley's $W(9)=.11$, $p<.05, \varepsilon=.49$. Therefore, all within-subjects values cited are HyunhFeldt corrected. The main effect for the between subjects variable, GROUP, was significant, $F(2,84)=3.52, p<.05$, partial $\eta^{2}=.08$, observed power $=.64$. The main effect for the within subjects variable, BAND, was significant, $F(1.96,164.43)=75.24, p<.05$, partial $\eta^{2}=.47$, observed power $=1.0$. The GROUP by BAND interaction was significant, $F(3.92,164.43)=4.48, p<.05$, partial $\eta^{2}=.10$, observed power $=.93$. Given these results, post hoc tests were conducted on the GROUP by BAND interaction. A Bonferroni corrected alpha level of .01 was used to adjust for multiple comparisons. Analysis of simple main effects, utilizing five separate one-way ANOVAs (splitting the file by BAND), revealed that the interaction of GROUP $\times$ BAND was not driven by group asymmetry differences at post-test in the delta, theta, alpha, or beta bands (no significant group differences in these bands). However, significant group differences at post-test emerged in the gamma band, $F$ ( 2 , $164.43)=5.30, p<.01$. Follow-up Tukey tests indicated that the EXP and TYP groups did not significantly differ from each other in gamma asymmetry at post-test; however, the WL group continued to have significantly lower left-dominant gamma asymmetry at post-test than the TYP group (EXP POST mean $=-.85$, WL POST mean $=-.48$, TYP mean $=-1.23$ ). Thus, these results suggest that the ASD group that completed PEERS had neural asymmetry patterns that were characterized by more left-dominant asymmetry in gamma bands, not significantly different from a typically developing group of adolescents. In contrast, the ASD group who did not complete PEERS continued to have significantly less left-dominant gamma EEG asymmetry at posttest versus a group of typically developing adolescents (see Fig. 4). 


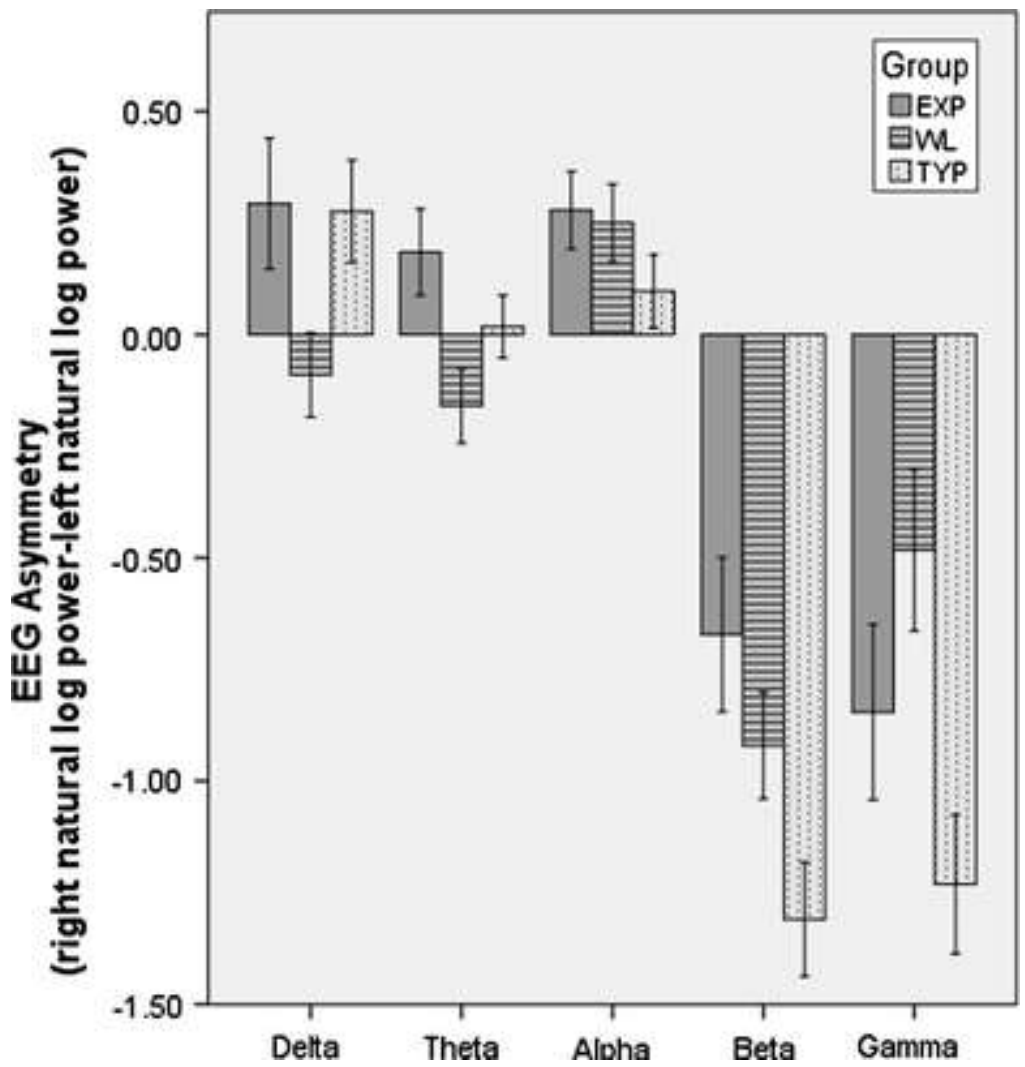

Fig. 4. EEG Asymmetry in Adolescents with ASD at Post-test versus Typically Developing Adolescents. Note Values are mean EEG asymmetry at post-test by group, calculated as (natural log right hemisphere power) minus (natural log left hemisphere power). Thus, more negative values indicate relatively greater left hemisphere EEG power. EXP = adolescents with ASD who completed PEERS intervention between preand post-test measures; WL = adolescents with ASD who did not complete PEERS intervention between pre- and post-test measures; TYP = typically developing adolescents (measured on one occasion). Delta $(0-4 \mathrm{~Hz})$, Theta (4-8 Hz), Alpha (8$12 \mathrm{~Hz})$, Beta $(12-30 \mathrm{~Hz})$, and Gamma $(30-50 \mathrm{~Hz})$ EEG frequency bands are plotted on the $X$ axis

\section{Discussion}

Recently, researchers have begun placing more emphasis on developing and assessing "neurally inspired behavioral therapies" (Davidson 2012, p. 153). The first aim of this study was to investigate whether neural asymmetry would differentially change in adolescents with ASD who participated in a randomized controlled trial of the PEERS relationship-development intervention. Results indicated that adolescents with ASD who completed the PEERS intervention showed a shift from right-hemisphere dominant EEG activity before PEERS to a left-hemisphere dominant pattern of EEG activity after PEERS was 
completed. In comparison, adolescents with ASD in the waitlist control group did not show this change in hemispheric dominance over time. The shift in the experimental group was noted as occurring specifically in the gamma (30-50 Hz) band. To our knowledge, this is the first study demonstrating that social-behavioral intervention is associated with changes in neural activity in adolescents with ASD.

The second aim of this study was to examine relations between asymmetry and social approach behavior or social knowledge: specifically, whether neural asymmetry was related to symptoms of autism, amount of social contacts, or acquisition of intervention concepts by the adolescents with ASD. First, this study found the following changes in social-behavioral measures specific to the experimental group who completed PEERS: (1) a decrease in parentrated symptoms of autism, (2) an increase in the number of social contacts, via get-togethers with other adolescents, and (3) an increase in social skills knowledge and concepts targeted by the PEERS intervention. Therefore, behaviorally, the adolescents in this study responded similarly to prior published work on PEERS (Laugeson et al. 2009, 2012), providing a partial independent replication of the efficacy of the intervention. Importantly, social-behavior, as rated by parents, was significantly related to the degree of left-hemisphere EEG dominance. Specifically, adolescents with ASD who showed a greater left-hemisphere gamma dominance pattern at post-test also showed fewer parent-rated symptoms of autism. Secondly, adolescents who showed greater left-hemisphere gamma dominance at post-test also showed more knowledge of PEERS concepts. Lastly, adolescents who showed greater left-hemisphere gamma dominance at post-test also reported more social contacts, via both initiated and invited gettogethers with other adolescents. Thus, it appears that social behavior, understanding, and exposure were related to the degree of leftdominant pattern of hemispheric asymmetry in adolescents with ASD post-intervention.

The third aim was designed primarily to put the findings on gamma asymmetry in context. To our knowledge, no prior study has examined gamma asymmetry in typically developing adolescents, and so this aim was designed to compare EEG asymmetry in the groups of adolescents with ASD to a group of typically developing adolescents. Of particular interest was whether these comparisons would change 
based on the provision on PEERS treatment to the experimental group of adolescents with ASD. First, adolescents with ASD did not differ from each other at pre-test, but both showed significantly less relative left-dominant neural asymmetry in high-frequency EEG bands as compared to adolescents without ASD. In other words, it appears that adolescents without ASD can be characterized by a pattern of relatively more activation in high-frequency bands in the left hemisphere, whereas adolescents with ASD, prior to PEERS intervention, show less activation in these indices. However, these patterns change when comparing the adolescents with ASD at posttest to typically developing adolescents, when one group had received the PEERS intervention. In this analysis, follow-up tests indicated that the significant interaction was due to the group of adolescents with ASD, who did not receive PEERS, still showing less dominant lefthemisphere activity in the high-frequency gamma band versus typically developing adolescents. In contrast, the group of adolescents who received PEERS no longer significantly differed from the typically developing adolescents in this index. In essence, after intervention, the degree of left-dominant neural activation in adolescents with ASD approximated that of the adolescents without ASD. It may be presumptuous to describe this as a "normalization" of left-dominant asymmetry, especially given that the degree of asymmetry in the experimental-group of adolescents with ASD was still descriptively less (although not significantly less) than that of the typically developing group (see Fig. 4). However, it is still very encouraging that participation in the PEERS intervention resulted in neural asymmetry patterns in ASD that no longer significantly differed from a typically developing group. It will be crucial to examine this pattern at a longterm follow-up to determine if change in this index is stable and continues to approximate the pattern seen here in typically developing adolescents, especially as adolescents with ASD might continue to make social and behavioral gains in their friendship skills and contacts. In sum, this finding represents the first evidence of neural change in ASD due to social skills/relationship intervention, as compared to pretest measures, that approximates patterns in typical development. It may be that adolescence is another window for neural and behavioral plasticity in ASD, and that effective interventions should be targeted to this dynamic developmental window. 
A recent study (Dawson et al. 2012) examined neural activity in toddlers with ASD who participated in the Early Start Denver Model (ESDM: Dawson et al. 2010) intervention. Toddlers with ASD were compared on EEG activation to a group of typically developing toddlers and a group of toddlers with ASD who received treatment as usual in the community. The study found that toddlers who received ESDM treatment "normalized" in their degree of theta and alpha EEG activation to repeated still images of faces. EEG was measured only at post-test, so it is impossible to know to what degree the children with ASD shifted in these indices from pre-intervention levels. In addition, gamma activity was filtered out of the data, and asymmetry was not calculated, so it is unknown whether differences similar to those observed in the present investigation might also have been noted. This is unfortunate considering a recent report that gamma activity in the first 3 years of life is significantly predictive of enhancements in and development of language, cognition, and shifting attention (Benasich et al. 2008), and other reports that gamma reflects long-range neural synchronization and connectivity (Engel et al. 2001; Varela et al. 2001), all of which have been noted to be negatively affected in ASD (Mundy et al. 1990; Wing 1981; Just et al. 2012). Regardless, the present study, in addition to Dawson et al. (2012) and several others (Bolte et al. 2006; Faja et al. 2012; Russo et al. 2010), provides mounting evidence that neural activity in ASD is responsive to socialbehavioral intervention across the lifespan.

Several important points regarding these findings should be considered. First, an intriguing issue is the consistency of gamma asymmetry differences relating to differences in social behavior. Prior work on asymmetry in ASD and other populations has focused on the alpha band asymmetry (cf., Davidson et al. 1990; Kylliäinen et al. 2012; Miskovic et al. 2010). To our knowledge, this study is the first to examine gamma band asymmetry, and, thus, the results here would benefit from replication before being extensively interpreted. However, recent work suggests that gamma and alpha are coupled, and that decreases in alpha may be related to increases in gamma bursts (Osipova et al. 2008). Similarly, additional studies have found that fMRI BOLD activation is correlated positively with gamma (Fiebach et al. 2006; Foucher et al. 2003) and negatively with alpha band power (Scheeringa et al. 2011). EEG gamma findings, thus, may have closer concordance with fMRI activation than other frequency bands, which 
may be helpful for synthesizing results across neuroimaging techniques and studies. Additionally, it is interesting that power in the gamma band is noted to support or reflect higher-order cognitive functions (Herrmann et al. 2004; Lutz et al. 2004), including stimulus binding (Frey et al. 2009; Ribary 2005) and coordination of the activity of inter-hemispheric neural areas via white matter tracts (Buzsáki and Wang 2012; Csicsvari et al. 2003; Rodriguez et al. 1999; Singer 1999). Perhaps, then, social-learning and positive social-environmental enrichment, gained via development of friendships, might propel dynamic neural changes in higher-order cognitive function and white matter development, and that this effect might be specific to the left hemisphere. This type of intervention benefit, if replicated via more indepth imaging studies, will be particularly important for developmental stages in which neural areas are already expected to develop and may be affected by experience, such as in adolescence (Gogtay et al. 2004; Barnea-Goraly et al. 2005).

Another point to consider is to more carefully examine elements of interventions and their link to topics related to known functions of neural systems. A large body of literature has established that one characteristic of an "adaptive path" for the brain is exhibited in lefthemisphere dominant asymmetry (Fox et al. 2001; Lopez-Duran et al. 2012; Miskovic et al. 2010; Mitchell and Pössel 2011; Smith and Bell 2010). Individuals who exhibit this neural pattern are characterized by more positive emotion and a style of approaching and interacting socially with the world (Davidson et al. 1990; Davidson 1998; Sutton and Davidson 1997). Table $\underline{2}$ details the topics covered in PEERS sessions. This material is reproduced from the PEERS manual (Laugeson and Frankel 2010a, b) , but a novel element added here is the third column, detailing which aspects of the PEERS sessions directly or indirectly facilitate social approach. The primary focus of PEERS is for adolescents to make and keep friends; a large portion of this goal inherently involves approaching others. Thus, it is noteworthy that the adolescents with ASD, who completed PEERS, also showed a shift to more left-hemisphere dominant neural asymmetry, more closely approximating the pattern seen in typically developing adolescents. It may be that teaching high-functioning adolescents the unwritten rules of social interaction, via an intervention such as PEERS, provides them with the tools necessary to approach others and thereby enrich their own social environments, similar to the increased

Journal of Autism and Developmental Disorders, Vol 45, No. 2 (February 2015): pg. 316-335. DOI. This article is (C) Springer and permission has been granted for this version to appear in e-Publications@Marquette. Springer does not grant permission for this article to be further copied/distributed or hosted elsewhere without the express permission from Springer. 
focus on peers seen in typically developing adolescents. Relatedly, it may be important to consider the effect gaining a network of peers has on the development of high-functioning adolescents with ASD, given that adolescence is a developmental period in which the bulk of social learning opportunities typically shifts from parents to peers (Steinberg and Morris 2001). Increased social peer contacts may result in longterm changes in learning opportunities, past the termination of treatment. Thus, it may be important not to underestimate the effect of peers on the development of social behavior in adolescents with ASD. Given the deleterious effects of social isolation and loneliness on health and well-being (Cacioppo and Hawkley 2009; Hawkley and Cacioppo 2010; Holt-Lunstad et al. 2010; Uchino et al. 1996), it seems important that these areas receive continued attention from researchers and interventionists.

A third and last point concerns heterogeneity and comorbidity in ASD. A well-documented phenomenon, especially in high-functioning samples, is that of high rates of depression, withdrawal, anxiety, and negative affect or mood in ASD (Kim et al. 2000; Meyer et al. 2006; Schwartz et al. 2009). Given the links of depression/negative mood with right-hemisphere dominance (Pizzagalli et al. 2005; Sutton and Davidson 1997), it will be important for future treatment research to examine whether these co-occurring negative mood states are a cardinal aspect of the autism taxon, or are a true, separable, additional challenge experienced by many individuals on the autism spectrum. The Modifier Model of Autism (Mundy et al. 2007) presents a theoretical framework that may be helpful in this regard. The model posits that initial causal processes (ICP) of autism interact with potential modifier processes (MP) to influence the development and expression of characteristics of persons affected by autism spectrum disorders. Importantly, modifier processes, such as temperament/personality, cognitive style, and approach orientation, produce individual differences in well-being outcomes experienced by all people (Mundy et al. 2007). These modifiers may also affect the phenotypic presentation and course of ASD, especially in highfunctioning individuals (Burnette et al. 2011; Meyer et al. 2006; Mundy et al. 2007; Sutton et al. 2005). Thus, it will be important to consider that treatments for ASD affecting these modifier processes may enhance well-being and adjustment via meeting psychological 
needs, such as remediation of isolation, that are important for all people.

Although this study provides new information on neural plasticity in response to treatment in adolescents with ASD, there are several important limitations that deserve mention. First, and foremost, it is likely too early to judge whether a change to leftdominant asymmetry is ultimately a completely positive outcome for this population, as the literature in this area is somewhat mixed. For example, one study found that individuals with high-functioning ASD and relatively intact left-hemisphere dominance also reported more awareness of social limitations and difficulty (Sutton et al. 2005). Studies have also linked left-anterior dominance with symptoms of anxious apprehension in typically developing adults (Heller et al. 1997; Mathersul et al. 2008). Thus, it will be important to conduct long-term follow-up studies to determine both whether the shifts in asymmetry are stable, and if so, the implications of this shift for adjustment and positive mood in ASD. Related to this point, the current study would also have benefited from measures of adolescent mood, approach orientation, and ecologically valid in vivo social skills at pre- and posttest. It may be that adolescents with ASD who are motivated to learn how to make friends, one of the entrance criteria for this study, are different in baseline approach orientation from other groups of adolescents with ASD. Also, the two groups of adolescents with ASD in this study, although not statistically different on age (and results were not affected by covarying age out of the analyses), did vary somewhat in that the average age of the experimental group was somewhat older than the waitlist control group. However, given that most evidence for anatomical neural growth and plasticity emphasizes that more robust changes occur earlier in adolescence versus later (Thompson et al. 2000), it is doubtful that the changes in this domain in the slightly older experimental group would be due to age. Additionally, as this study focused on baseline activity, it will be valuable for future studies to examine EEG plasticity due to intervention during stimuli presentation, tasks, and evoked gamma procedures. Lastly, pre-post ratings of autism symptoms from unbiased observers would also have been helpful in eliminating any potential caregiver reporting bias in the experimental group. Future studies and replication efforts will need to address these issues before further conclusions can be drawn. 
Even when considering the limitations of this study, however, the findings suggest several interesting future directions. First, it will be important for future work to examine statistical directionality of neural changes due to intervention, i.e., do neural asymmetry shifts occur first and drive behavioral change, or vice versa, or perhaps are these shifts truly concurrent? Studies that have more frequent measures of neural activity over the course of intervention will be helpful for this purpose. Another intriguing area to investigate is functional neural directionality. We previously reported preliminary data suggesting that right- to left-frontal and right- to left-parietal interhemispheric EEG coherence, a measure of connectivity, increased in a separate sample of adolescents who participated in PEERS (Vaughan Van Hecke et al. 2012). If a shift to left-dominant asymmetry occurs due to intervention in this population, then, it will be important to investigate how this change is accomplished (e.g., one possibility might be via the anterior and posterior corpus callosum white matter tracts that connect the right and left hemispheres: Lewis et al. 2012). Imaging of structural white matter integrity and connectivity, and functional neural connectivity (e.g., EEG coherence), before and after intervention may shed light on these questions. Further, imaging studies of potential changes in the activation of deeper cortical and subcortical structures, including the limbic system and measures of subcortical regulation of approach or withdrawal/flight states (e.g., Koslov et al. 2011) may also highlight whether plasticity of emotion circuitry and autonomic regulation contribute to intervention outcomes in ASD.

Recent recommendations (Davidson 2012; McPartland and Pelphrey 2012) suggest that, in the coming years, an increasing emphasis should be placed on verifying whether and how effective treatments for psychological disorders affect neural structure and function. The current study comprises an important first effort at identifying whether effective therapies for adolescents with ASD affect functional neural asymmetry. Adolescents who completed the PEERS friendship-development intervention showed a shift from right- to lefthemisphere dominant EEG asymmetry, and a greater magnitude of left-dominant asymmetry related to fewer symptoms of autism, more social contacts, and more knowledge of intervention concepts. After completing the PEERS intervention, patterns of left-hemisphere dominant neural asymmetry in adolescents with ASD no longer and permission has been granted for this version to appear in e-Publications@Marquette. Springer does not grant permission for this article to be further copied/distributed or hosted elsewhere without the express permission from Springer. 
significantly differed from a typically developing comparison group. Thus, it may be that adolescent neural function in ASD is experienceexpectant, and responds to the development of friendships and the remediation of social isolation during this critical developmental period.

\section{Acknowledgments}

This research was supported by a Research Development Grant and a Regular Research Grant from Marquette University, and a Grant from the Autism Society of Southeastern Wisconsin. We would like to acknowledge undergraduate assistants Chelsea Gasaway, Grand McDonald, Noelle Fritz, Alexandra Reveles, Jenna Kahne, and Janel Wasisco. We also wish to thank Elizabeth Laugeson, Psy.D., UCLA, for her assistance in starting the PEERS program in Wisconsin, and the families that participated for their time and dedication to clinical research.

\section{References}

Achenbach, T., \& Rescorla, L. (2001). Manual for the ASEBA school-age forms and profiles: An integrated system of multi-informant assessment. ASEBA.

American Psychiatric Association. (2000). Diagnostic and statistical manual of mental disorders (4th ed.). Washington, DC: Author.

Anderson, D., Maye, M., \& Lord, C. (2011). Changes in maladaptive behaviors from midchildhood to young adulthood in autism spectrum disorder. American Journal on Intellectual and Developmental Disabilities, 116, 381-397.

Ashwin, C., Wheelwright, S., \& Baron-Cohen, S. (2005). Laterality biases to chimeric faces in Asperger syndrome: What is right about faceprocessing? Journal of Autism and Developmental Disorders, 35(2), 183-196.

Banaschewski, T., \& Brandeis, D. (2007). Annotation: What electrical brain activity tells us about brain function that other techniques cannot tell us-a child psychiatric perspective. Journal of Child Psychology and Psychiatry, 48(5), 415-435.

Barnea-Goraly, N., Menon, V., Eckert, M., et al. (2005). White matter development during childhood and adolescence: A cross-sectional diffusion tensor imaging study. Cerebral Cortex, 15, 1848-1854.

Barnhill, G., Cook, K., Tebbenhamp, K., \& Myles, B. (2002). The effectiveness of social skills Intervention targeting nonverbal communication for adolescents with Asperger syndrome and related pervasive developmental delays. Focus on Autism and Other Developmental Disabilities, 17, 112-118.

Journal of Autism and Developmental Disorders, Vol 45, No. 2 (February 2015): pg. 316-335. DOI. This article is (C) Springer and permission has been granted for this version to appear in e-Publications@Marquette. Springer does not grant permission for this article to be further copied/distributed or hosted elsewhere without the express permission from Springer. 
NOT THE PUBLISHED VERSION; this is the author's final, peer-reviewed manuscript. The published version may be accessed by following the link in the citation at the bottom of the page.

Bauminger, N., \& Kasari, C. (2000). Loneliness and friendship in highfunctioning children with autism. Child Development, 71, 447-456.

Baving, L., Laucht, M., \& Schmidt, M. H. (2002). Frontal brain activation in anxious school children. Journal of Child Psychology and Psychiatry, $43(2), 265-274$.

Beglinger, L., \& Smith, T. (2005). Concurrent validity of social subtype and IQ after early intensive behavioral intervention in children with autism: A preliminary investigation. Journal of Autism and Developmental Disorders, 35(3), 295-303.

Benasich, A., Gou, Z., Choudhury, N., \& Harris, K. (2008). Early cognitive and language skills are linked to resting frontal gamma power across the first three years. Behavioral Brain Research, 195, 215-222.

Black, J., Jones, T., Nelson, C., \& Greenough, W. (1998). Neuronal plasticity and the developing brain. In N. Alessi, J. Coyle, S. Harrison, \& S. Eth (Eds.), Handbook of child and adolescent psychiatry (pp. 31-53). New York: Wiley.

Blakemore, S. (2008). The social brain in adolescence. Nature Reviews Neuroscience, 9, 267-277.

Boles, D. B., Barth, J. M., \& Merrill, E. C. (2008). Asymmetry and performance: Toward a neurodevelopmental theory. Brain and Cognition, 66, 124-139.

Bolte, S., Hubl, D., Feineis-Matthews, S., Prvulovic, D., Dierks, T., \& Poustka, F. (2006). Facial affect recognition training in autism: Can we animate the fusiform gyrus? Behavioral Neuroscience, 120, 211-216.

Burnette, C. P., Henderson, H. A., Inge, A. P., Zahka, N. E., Schwartz, C. B., \& Mundy, P. C. (2011). Anterior EEG asymmetry and the modifier model of autism. Journal of Autism and Developmental Disorders, 41(8), 1113-1124.

Buzsáki, G., \& Wang, X. J. (2012). Mechanisms of gamma oscillations. Annual Review of Neuroscience, 35, 203-225.

Cacioppo, J. T., \& Hawkley, L. C. (2009). Perceived social isolation and cognition. Trends in Cognitive Sciences, 13(10), 447-454.

Cacioppo, J. T., Norris, C. J., Decety, J., Monteleone, G., \& Nusbaum, H. (2009). In the eye of the beholder: Individual differences in perceived social isolation predict regional brain activation to social stimuli. Journal of Cognitive Neuroscience, 21(1), 83-92.

Chiron, C., Leboyer, M., Leon, F., Jambaque, L., Nuttin, C., \& Syrota, A. (1995). SPECT of the brain in childhood autism: Evidence for a lack of normal hemispheric asymmetry. Developmental Medicine and Child Neurology, 37(10), 849-860.

Constantino, J. (2005). Social responsiveness scale. Los Angeles: Western Psychological Services.

Journal of Autism and Developmental Disorders, Vol 45, No. 2 (February 2015): pg. 316-335. DOI. This article is @ Springer and permission has been granted for this version to appear in e-Publications@Marquette. Springer does not grant permission for this article to be further copied/distributed or hosted elsewhere without the express permission from Springer. 
Constantino, J. N., Davis, S. A., Todd, R. D., Schindler, M. K., Gross, M. M., Brophy, S. L., et al. (2003). Validation of a brief quantitative measure of autistic traits: Comparison of the social responsiveness scale with the autism diagnostic interview-revised. Journal of Autism and Developmental Disorders, 33(4), 427-433.

Cotter, M. (1997). Improving the social behavior of high-functioning children with autism: A social skills support group intervention. Unpublished doctoral dissertation, University of Alabama.

Csicsvari, J., Jamieson, B., Wise, K. D., \& Buzsáki, G. (2003). Mechanisms of gamma oscillations in the hippocampus of the behaving rat. Neuron, $37(2), 311-322$.

Davidson, R. J. (1998). Anterior electrophysiological asymmetries, emotion, and depression: Conceptual and methodological conundrums. Psychophysiology, 35(05), 607-614.

Davidson, R. J. (2012). The emotional life of your brain. New York: Penguin Books.

Davidson, R. J., Ekman, P., Saron, C. D., Senulis, J. A., \& Friesen, W. V. (1990). Approach-withdrawal and cerebral asymmetry: Emotional expression and brain physiology: I. Journal of Personality and Social Psychology, 58(2), 330.

Davidson, R. J., Kabat-Zinn, J., Schumacher, J., Rosenkranz, M., Muller, D., Santorelli, S. F., et al. (2003). Alterations in brain and immune function produced by mindfulness meditation. Psychosomatic Medicine, 65(4), 564-570.

Davidson, R. J., \& McEwen, B. S. (2012). Social influences on neuroplasticity: Stress and interventions to promote well-being. Nature Neuroscience, 15(5), 689-695

Dawson, G. (1983). Lateralized brain dysfunction in autism: Evidence from the Halstead-Reitan Neuropsychological Battery. Journal of Autism and Developmental Disorders, 13(3), 269-286.

Dawson, G. (2008). Early behavioral intervention, brain plasticity, and the prevention of autism spectrum disorder. Development and Psychopathology, 20, 775-803.

Dawson, G., \& Fernald, M. (1987). Perspective-taking ability and its relationship to the social behavior of autistic children. Journal of Autism and Developmental Disorders, 17(4), 487-498.

Dawson, G., Finley, C., Phillips, S., \& Galpert, L. (1986). Hemispheric specialization and the language abilities of autistic children. Child Development, 57, 1440-1453.

Dawson, G., Klinger, L. G., Panagiotides, H., Lewy, A., \& Castelloe, P. (1995). Subgroups of autistic children based on social behavior display distinct patterns of brain activity. Journal of Abnormal Child Psychology, 23(5), 569-583. 
NOT THE PUBLISHED VERSION; this is the author's final, peer-reviewed manuscript. The published version may be

accessed by following the link in the citation at the bottom of the page.

Dawson, G., Warrenburg, S., \& Fuller, P. (1982). Cerebral lateralization in individuals diagnosed as autistic in early childhood. Brain and Language, 15(2), 353-368.

Dawson, G., et al. (2010). Randomized, controlled trial of an intervention for toddlers with autism: The Early Start Denver Model. Pediatrics, 125, e17-e23.

Dawson, G., et al. (2012). Early behavioral intervention is associated with normalized brain activity in young children with autism. Journal of the American Academy of Child and Adolescent Psychiatry, 51, 11501159.

Delorme, A., \& Makeig, S. (2004). EEGLAB: An open source toolbox for analysis of single-trial EEG dynamics including independent component analysis. Journal of Neuroscience Methods, 134(1), 9-21.

Ehlers, S., Gillberg, C., \& Wing, L. (1999). A screening questionnaire for Asperger syndrome and other high-functioning autism spectrum disorders in school-age children. Journal of Autism and Developmental Disorders, 29, 129-141.

Engel, A., Fries, P., \& Singer, W. (2001). Dynamic predictions: Oscillations and synchrony in top-down processing. Nature Reviews Neuroscience, 2, 704-716.

Eussen, M. L., Van Gool, A. R., Verheij, F., De Nijs, P. F., Verhulst, F. C., \& Greaves-Lord, K. (2012). The association of quality of social relations, symptom severity and intelligence with anxiety in children with autism spectrum disorders. Autism, Oct 8, 2012 Epub ahead of print.

Faja, A., Webb, S., Jones, E., Merkle, K., Kamara, D., Bavaro, J., et al. (2012). The effects of face expertise training on the behavioral performance and brain activity of adults with high-functioning autism spectrum disorders. Journal of Autism and Developmental Disorders, 42, 278-293.

Fiebach, C., Rissman, J., \& D'Esposita, M. (2006). Modulation of inferotemporal cortex activation during working memory maintenance. Neuron, 51, 251-261.

Fone, K. C., \& Porkess, M. V. (2008). Behavioural and neurochemical effects of post-weaning social isolation in rodents-Relevance to developmental neuropsychiatric disorders. Neuroscience and Biobehavioral Reviews, 32(6), 1087-1102.

Foucher, J., Otzenberger, H., \& Gounot, D. (2003). The BOLD response and gamma oscillations respond differently than evoked potentials: An interleaved EEG-fMRI study. BMC Neuroscience, 4, 22.

Fox, N. A. (1991). If it's not left, it's right: Electroencephalograph asymmetry and the development of emotion. American Psychologist, 46(8), 863.

Journal of Autism and Developmental Disorders, Vol 45, No. 2 (February 2015): pg. 316-335. DOI. This article is (C) Springer and permission has been granted for this version to appear in e-Publications@Marquette. Springer does not grant permission for this article to be further copied/distributed or hosted elsewhere without the express permission from Springer. 
NOT THE PUBLISHED VERSION; this is the author's final, peer-reviewed manuscript. The published version may be

accessed by following the link in the citation at the bottom of the page.

Fox, N. A. (1994). Dynamic cerebral processes underlying emotion regulation. Monographs of the Society for Research in Child Development, 59(23), 152-166.

Fox, N. A., Henderson, H. A., Rubin, K. H., Calkins, S. D., \& Schmidt, L. A. (2001). Continuity and discontinuity of behavioral inhibition and exuberance: Psychophysiological and behavioral influences across the first four years of life. Child Development, 72(1), 1-21.

Frankel, F., \& Myatt, R. (2003). Children's friendship training. New York: Brunner-Routledge.

Frankel, F., \& Myatt, R. (2007). Parent-assisted friendship training for children with autism spectrum disorders: Effects associated with psychotropic medication. Child Psychiatry and Human Development, 37, 337-346.

Frey, H. P., Naber, M., Einhäuser, W., \& Foxe, J. (2009). The role of Gamma oscillations in binding ambiguous visual input into coherent percepts. Journal of Vision, 9(8), 923.

Gabbard, G. (2000). A neurobiologically informed perspective on psychotherapy. British Journal of Psychiatry, 177, 117-122.

Ghaziuddin, M., \& Zafar, S. (2008). Psychiatric comorbidity of adults with autism spectrum disorders. Clinical Neuropsychiatry: Journal of Treatment Evaluation, 5, 9-12.

Giedd, J., Blumenthal, J., Jeffries, N., Castellanos, F., Liu, H., Zijdenbos, A., et al. (1999). Brain development during childhood and adolescence: A longitudinal MRI study. Nature Neuroscience, 2, 861-863.

Gogtay, N., Giedd, J. N., Lusk, L., Hayashi, K. M., Greenstein, D., Vaituzis, A. C., et al. (2004). Dynamic mapping of human cortical development during childhood through early adulthood. Proceedings of the National Academy of Sciences of the United States of America, 101(21), 81748179.

Gogtay, N., \& Thompson, P. M. (2010). Mapping gray matter development: Implications for typical development and vulnerability to psychopathology. Brain and Cognition, 72(1), 6.

Gray, J. A., \& McNaughton, N. (2000). Fundamentals of the septohippocampal system. In J. A. Gray \& N. McNaughton (Eds.), Neuropsychology of anxiety (2nd ed.). Oxford, UK: Oxford University Press.

Greene, D. J., Colich, N., Iacoboni, M., Zaidel, E., Bookheimer, S. Y., \& Dapretto, M. (2011). Atypical neural networks for social orienting in autism spectrum disorders. NeuroImage, 56(1), 354-362.

Greenough, W. T., \& Black, J. E. (1992). Induction of brain structure by experience: Substrates for cognitive development. In M. R. Gunnar \& C. A. Nelson (Eds.), Developmental and behavioral neuroscience: The

Journal of Autism and Developmental Disorders, Vol 45, No. 2 (February 2015): pg. 316-335. DOI. This article is (C) Springer and permission has been granted for this version to appear in e-Publications@Marquette. Springer does not grant permission for this article to be further copied/distributed or hosted elsewhere without the express permission from Springer. 
NOT THE PUBLISHED VERSION; this is the author's final, peer-reviewed manuscript. The published version may be accessed by following the link in the citation at the bottom of the page.

Minnesota symposia on child psychology, Vol. 24 (pp. 155-200). Hillsdale, NJ: Lawrence Erlbaum.

Gunter, H. L., Ghaziuddin, M., \& Ellis, H. D. (2002). Asperger syndrome: Tests of right hemisphere functioning and interhemispheric communication. Journal of Autism and Developmental Disorders, 32(4), 263-281.

Güntürkün, O., \& Manns, M. (2010). The embryonic development of visual asymmetry in the pigeon. In K. Hugdahl \& R. Westerhausen (Eds.), The two halves of the brain (pp. 121-142). Cambridge, MA: The MIT Press.

Hawkley, L. C., \& Cacioppo, J. T. (2010). Loneliness matters: A theoretical and empirical review of consequences and mechanisms. Annals of Behavioral Medicine, 40(2), 218-227.

Haznedar, M., Buchsbaum, M., Hazlett, E., LiCalzi, E., Cartwright, C., \& Hollander, E. (2006). Volumetric analysis and three-dimensional glucose metabolic mapping of the striatum and thalamus in patients with autism spectrum disorders. American Journal of Psychiatry, 163(7), 1252-1263.

Heinrich, L. M., \& Gullone, E. (2006). The clinical significance of loneliness: A literature review. Clinical Psychology Review, 26(6), 695-718.

Heller, W., Nitschke, J. B., \& Lindsay, D. L. (1997). Neuropsychological correlates of arousal in self-reported emotion. Cognition and Emotion, 11(4), 383-402.

Herbert, M. R., Ziegler, D. A., Deutsch, C. K., O'Brien, L. M., Kennedy, D. N., Filipek, P. A., et al. (2005). Brain asymmetries in autism and developmental language disorder: A nested whole-brain analysis. Brain, 128(1), 213-226.

Herbert, M. R., Ziegler, D. A., Makris, N., Filipek, P. A., Kemper, T. L., Normandin, J. J., et al. (2004). Localization of white matter volume increase in autism and developmental language disorder. Annals of Neurology, 55(4), 530-540.

Herrmann, C. S., Munk, M. H., \& Engel, A. K. (2004). Cognitive functions of gamma-band activity: Memory match and utilization. Trends in Cognitive Sciences, 8(8), 347-355.

Holt-Lunstad, J., Smith, T. B., \& Layton, J. B. (2010). Social relationships and mortality risk: A meta-analytic review. PLoS Medicine, 7(7), e1000316.

Howell, D. C. (2012). Statistical methods for psychology (8th ed.). Belmont, CA: Wadsworth.

Huttenlocher, P., \& de Courten, C. (1987). The development of synapses in striate cortex of man. Human Neurobiology, 6, 1-9.

Just, M., Keller, T., Malave, V., Kana, R., \& Varma, S. (2012). Autism as a neural systems disorder: A theory of frontal-posterior 
NOT THE PUBLISHED VERSION; this is the author's final, peer-reviewed manuscript. The published version may be accessed by following the link in the citation at the bottom of the page.

underconnectivity. Neuroscience and Biobehavioral Reviews, 36, 1292-1313.

Kaufman, A., \& Kaufman, N. (2005). Kaufman brief intelligence test (2nd ed.). Circle Pines, MN: American Guidance Service.

Kim, J. A., Szatmari, P., Bryson, S. E., Streiner, D. L., \& Wilson, F. J. (2000). The prevalence of anxiety and mood problems among children with autism and Asperger syndrome. Autism, 4(2), 117-132.

Kleinhans, N., Richards, T., Sterling, L., Stegbauer, K., Mahurin, R., Johnson, L., et al. (2008). Abnormal functional connectivity in autism spectrum disorders during face processing. Brain, 131, 1000-1012.

Koslov, K., Mendes, W. B., Pajtas, P. E., \& Pizzagalli, D. A. (2011). Asymmetry in resting intracortical activity as a buffer to social threat. Psychological Science, 22(5), 641-649.

Kross, E., Berman, M. G., Mischel, W., Smith, E. E., \& Wager, T. D. (2011). Social rejection shares somatosensory representations with physical pain. Proceedings of the National Academy of Sciences, 108(15), 6270-6275.

Kylliäinen, A., Wallace, S., Coutanche, M. N., Leppänen, J. M., Cusack, J., Bailey, A. J., et al. (2012). Affective-motivational brain responses to direct gaze in children with autism spectrum disorder. Journal of Child Psychology and Psychiatry, 53, 790-797.

Lasgaard, M., Nielsen, A., Eriksen, M. E., \& Goossens, L. (2010). Loneliness and social support in adolescent boys with autism spectrum disorders. Journal of Autism and Developmental Disorders, 40(2), 218-226.

Laugeson, E., \& Frankel, F. (2010a). Social skills for teenagers with developmental and autism spectrum disorders: The PEERS treatment manual. New York: Routledge.

Laugeson, E., \& Frankel, F. (2010b). Adolescent mental status checklist. In The PEERS Treatment Manual. New York: Routledge.

Laugeson, E. A., Frankel, F., Gantman, A., Dillon, A. R., \& Mogil, C. (2012). Evidence-based social skills training for adolescents with autism spectrum disorders: The UCLA PEERS Program. Journal of Autism and Developmental Disorders, 42(6), 1025-1036.

Laugeson, E., Frankel, F., Mogil, C., \& Dillon, A. (2009). Parent-assisted social skills training to improve friendships in teens with autism spectrum disorders. Journal of Autism and Developmental Disorders, 39, 596606.

Lewis, J., Theilmann, R., Fonov, V., Bellec, P., Lincoln, A., Evans, A., et al. (2012). Callosal fiber length and interhemispheric connectivity in adults with autism: Brain overgrowth and underconnectivity. Human Brain Mapping, . doi:10.1002/hbm.22018.

Lo, Y. C., Soong, W. T., Gau, S. S. F., Wu, Y. Y., Lai, M. C., Yeh, F. C., et al. (2011). The loss of asymmetry and reduced interhemispheric

Journal of Autism and Developmental Disorders, Vol 45, No. 2 (February 2015): pg. 316-335. DOI. This article is @ Springer and permission has been granted for this version to appear in e-Publications@Marquette. Springer does not grant permission for this article to be further copied/distributed or hosted elsewhere without the express permission from Springer. 
NOT THE PUBLISHED VERSION; this is the author's final, peer-reviewed manuscript. The published version may be accessed by following the link in the citation at the bottom of the page.

connectivity in adolescents with autism: A study using diffusion spectrum imaging tractography. Psychiatry Research: Neuroimaging, 192(1), 60-66.

Lopata, C., Toomey, J. A., Fox, J. D., Volker, M. A., Chow, S. Y., Thomeer, M. L., et al. (2010). Anxiety and depression in children with HFASDs: Symptom levels and source differences. Journal of Abnormal Child Psychology, 38(6), 765-776.

Lopez-Duran, N. L., Nusslock, R., George, C., \& Kovacs, M. (2012). Frontal EEG asymmetry moderates the effects of stressful life events on internalizing symptoms in children at familial risk for depression. Psychophysiology, 49, 510-521.

Lord, C., Rutter, M., Dilavore, P., \& Risi, S. (1999). Autism diagnostic observation schedule (ADOS). Los Angeles: Western Psychological Services.

Luciana, M. (2010). Adolescent brain development: Current themes and future directions. Introduction to the special issue. Brain and Cognition, 72(1), 1.

Lutz, A., Greischar, L. L., Rawlings, N. B., Ricard, M., \& Davidson, R. J. (2004). Long-term meditators self-induce high-amplitude gamma synchrony during mental practice. Proceedings of the National Academy of Sciences of the United States of America, 101(46), 16369-16373.

Makinodan, M., Rosen, K. M., Ito, S., \& Corfas, G. (2012). A critical period for social experience-dependent oligodendrocyte maturation and myelination. Science, 337(6100), 1357-1360.

Marsh, R., Gerber, A., \& Peterson, B. (2008). Neuroimaging studies of normal brain development and their relevance for understanding childhood neuropsychiatric disorders. Journal of the American Academy of Child and Adolescent Psychiatry, 47, 1233-1251.

Mathersul, D., Williams, L. M., Hopkinson, P. J., \& Kemp, A. H. (2008). Investigating models of affect: Relationships among EEG alpha asymmetry, depression, and anxiety. Emotion, 8(4), 560.

McPartland, J. C., \& Pelphrey, K. A. (2012). The implications of social neuroscience for social disability. Journal of Autism and Developmental Disorders, 42, 1256-1262.

Mehta, M. A., Golembo, N. I., Nosarti, C., Colvert, E., Mota, A., Williams, S. C., et al. (2009). Amygdala, hippocampal and corpus callosum size following severe early institutional deprivation: The English and Romanian adoptees study pilot. Journal of Child Psychology and Psychiatry, 50(8), 943-951.

Meyer, J. A., Mundy, P. C., Van Hecke, A. V., \& Durocher, J. S. (2006). Social attribution processes and comorbid psychiatric symptoms in children with Asperger syndrome. Autism, 10(4), 383-402.

Journal of Autism and Developmental Disorders, Vol 45, No. 2 (February 2015): pg. 316-335. DOI. This article is (C) Springer and permission has been granted for this version to appear in e-Publications@Marquette. Springer does not grant permission for this article to be further copied/distributed or hosted elsewhere without the express permission from Springer. 
NOT THE PUBLISHED VERSION; this is the author's final, peer-reviewed manuscript. The published version may be

accessed by following the link in the citation at the bottom of the page.

Minshew, N., \& Keller, T. (2010). The nature of brain dysfunction in autism: Functional brain imaging studies. Current Opinion in Neurology, 23, 124-130.

Miskovic, V., Schmidt, L. A., Georgiades, K., Boyle, M., \& Macmillan, H. L. (2010). Adolescent females exposed to child maltreatment exhibit atypical EEG coherence and psychiatric impairment: Linking early adversity, the brain, and psychopathology. Development and Psychopathology, 22(02), 419-432.

Mitchell, A. M., \& Pössel, P. (2011). Frontal brain activity pattern predicts depression in adolescent boys. Biological Psychology, 89, 525-527.

Mognon, A., Jovicich, J., Bruzzone, L., \& Buiatti, M. (2010). ADJUST: An automatic EEG artifact detector based on the joint use of spatial and temporal features. Psychophysiology, 48(2), 229-240.

Moncrieff, D. (2010). Hemispheric asymmetry in pediatric developmental disorders: Autism, attention-deficit/hyperactivity disorder, and dyslexia. In K. Hugdahl \& R. Westerhausen (Eds.), The two halves of the brain (pp. 561-602). Cambridge, MA: MIT Press.

Moscovitch, D. A., Santesso, D. L., Miskovic, V., McCabe, R. E., Antony, M. M., \& Schmidt, L. A. (2011). Frontal EEG asymmetry and symptom response to cognitive behavioral therapy in patients with social anxiety disorder. Biological Psychology, 87(3), 379-385.

Mundy, P. (1995). Joint attention and social-emotional approach behavior in children with autism. Development and Psychopathology, 7, 63-82.

Mundy, P. C. (2003). Annotation: The neural basis of social impairments in autism: The role of the dorsal medial-frontal cortex and anterior cingulate system. Journal of Child Psychology and Psychiatry and Allied Disciplines, 44, 793-809.

Mundy, P. C., Henderson, H. A., Inge, A. P., \& Coman, D. C. (2007). The modifier model of autism and social development in higher functioning children. Research and Practice for Persons with Severe Disabilities: The Journal of TASH, 32(2), 124.

Mundy, P., Sigman, M., \& Kasari, C. (1990). A longitudinal study of joint attention and language development in autistic children. Journal of Autism and Developmental Disorders, 20, 115-128.

Nelson, C. A. (2000). Neural plasticity and human development: The role of early experience in sculpting memory systems. Developmental Science, 3(2), 115-136.

Neuhaus, E., Beauchaine, T., \& Bernier, R. (2010). Neurobiological correlates of social functioning in autism. Clinical Psychology Review, 30, 733748.

Ong, A. D., Rothstein, J. D., \& Uchino, B. N. (2012). Loneliness accentuates age differences in cardiovascular responses to social evaluative threat. Psychology and Aging, 27(1), 190.

Journal of Autism and Developmental Disorders, Vol 45, No. 2 (February 2015): pg. 316-335. DOI. This article is (c) Springer and permission has been granted for this version to appear in e-Publications@Marquette. Springer does not grant permission for this article to be further copied/distributed or hosted elsewhere without the express permission from Springer. 
Osipova, D., Hermes, D., \& Jensen, O. (2008). Gamma power is phase-locked to posterior alpha activity. PLoS One, 3(12), e3990.

Ozonoff, S., \& Miller, J. (1995). Teaching theory of mind: A new approach to social skills training for individuals with autism. Journal of Autism and Developmental Disorders, 25, 415-533.

Palmer, J. A., Makeig, S., Kreutz-Delgado, K. \& Rao, B. D. (2008). Newton method for the ICA mixture model. In Proceedings of the 33rd IEEE International Conference on Acoustics and Signal Processing (ICASSP 2008), Las Vegas, NV, pp. 1805-1808.

Pardini, M., Elia, M., Garaci, F. G., Guida, S., Coniglione, F., Krueger, F., et al. (2012). Long-term cognitive and behavioral therapies, combined with augmentative communication, are related to uncinate fasciculus integrity in autism. Journal of Autism and Developmental Disorders, 42(4), 585-592.

Paus, T. (2010). Growth of white matter in the adolescent brain: Myelin or axon? Brain and Cognition, 72(1), 26-35.

Pizzagalli, D. A., Sherwood, R. J., Henriques, J. B., \& Davidson, R. J. (2005). Frontal brain asymmetry and reward responsiveness: A sourcelocalization study. Psychological Science, 16(10), 805-813.

Reichow, B., Steiner, A., \& Volkmar, F. (2013). Social skills groups for people aged 6 to 21 with autism spectrum disorders (ASD). Evidence-based Child Health: A Cochrane Review Journal, 8(2), 266-315.

Ribary, U. (2005). Dynamics of thalamo-cortical network oscillations and human perception. Progress in Brain Research, 150, 127-142.

Rinehart, N. J., Bradshaw, J. L., Brereton, A. V., \& Tonge, B. J. (2002). A clinical and neurobehavioural review of high-functioning autism and Asperger's disorder. Australian and New Zealand Journal of Psychiatry, 36(6), 762-770.

Rodriguez, E., George, N., Lachaux, J. P., Martinerie, J., Renault, B., \& Varela, F. J. (1999). Perception's shadow: Long-distance synchronization of human brain activity. Nature, 397(6718), 430-433.

Russo, N. M., Hornickel, J., Nicol, T., Zecker, S., \& Kraus, N. (2010). Biological changes in auditory function following training in children with autism spectrum disorders. Behavioral and Brain Functions, 6(1), 60.

Sabbagh, M. A. (1999). Communicative intentions and language: Evidence from right-hemisphere damage and autism. Brain and Language, 70(1), 29-69.

Scheeringa, R., et al. (2011). Neuronal dynamics underlying high- and lowfrequency EEG oscillations contribute independently to the human BOLD signal. Neuron, 69, 572-583. 
NOT THE PUBLISHED VERSION; this is the author's final, peer-reviewed manuscript. The published version may be

accessed by following the link in the citation at the bottom of the page.

Schmithorst, V. J., \& Yuan, W. (2010). White matter development during adolescence as shown by diffusion MRI. Brain and Cognition, 72(1), 16-25.

Schwartz, C. B., Henderson, H. A., Inge, A. P., Zahka, N. E., Coman, D. C., Kojkowski, N. M., et al. (2009). Temperament as a predictor of symptomotology and adaptive functioning in adolescents with highfunctioning autism. Journal of Autism and Developmental Disorders, 39(6), 842-855.

Shamay-Tsoory, S. G., Gev, E., Aharon-Peretz, J., \& Adler, N. (2010). Brain asymmetry in emotional processing in Asperger syndrome. Cognitive and Behavioral Neurology, 23(2), 74-84.

Shea, V., \& Mesibov, G. B. (2005). Adolescents and adults with autism. In F. R. Volkmar, R. Paul, A. Klin, \& D. Cohen (Eds.), Handbook of autism and pervasive developmental disorders, diagnosis, development, neurobiology, and behavior (3rd ed., pp. 288-311). New York, NY: Wiley.

Sherer, M. R., \& Schreibman, L. (2005). Individual behavioral profiles and predictors of treatment effectiveness for children with autism. Journal of Consulting and Clinical Psychology, 73(3), 525.

Sheridan, M. A., Fox, N. A., Zeanah, C. H., McLaughlin, K. A., \& Nelson, C. A. (2012). Variation in neural development as a result of exposure to institutionalization early in childhood. Proceedings of the National Academy of Sciences, 109(32), 12927-12932.

Singer, W. (1999). Striving for coherence. Nature, 397(4), 391-393.

Smith, C. L., \& Bell, M. A. (2010). Stability in infant frontal asymmetry as a predictor of toddlerhood internalizing and externalizing behaviors. Developmental Psychobiology, 52(2), 158-167.

Solomon, M., Goodlin-Jones, B., \& Anders, T. (2004). A social adjustment enhancement intervention for high functioning autism, Asperger's syndrome, and pervasive developmental disorder NOS. Journal of Autism and Developmental Disorders, 34, 649-668.

Sowell, E., Thompson, P., Holmes, C., Jernigan, T., \& Toga, A. (1999). In vivo evidence for post-adolescent brain maturation in frontal and striatal regions. Nature Neuroscience, 2, 859-861.

Steinberg, L., \& Morris, A. (2001). Adolescent development. Annual Review of Psychology, 52, 83-110.

Steinmetz, H., Herzog, A., Schlaug, G., Huang, Y., \& Jäncke, L. (1995). Brain (a) symmetry in monozygotic twins. Cerebral Cortex, 5(4), 296-300.

Stewart, M., Barnard, L., Pearson, J., Hasan, R., \& O'Brien, G. (2006). Presentation of depression in autism and Asperger syndrome. Autism, $10,103-116$.

Journal of Autism and Developmental Disorders, Vol 45, No. 2 (February 2015): pg. 316-335. DOI. This article is (C) Springer and permission has been granted for this version to appear in e-Publications@Marquette. Springer does not grant permission for this article to be further copied/distributed or hosted elsewhere without the express permission from Springer. 
Stroganova, T. A., Nygren, G., Tsetlin, M. M., Posikera, I. N., Gillberg, C., Elam, M., et al. (2007). Abnormal EEG lateralization in boys with autism. Clinical Neurophysiology, 118(8), 1842-1854.

Sutton, S. K., Burnette, C. P., Mundy, P. C., Meyer, J., Vaughan, A., Sanders, C., et al. (2005). Resting cortical brain activity and social behavior in higher functioning children with autism. Journal of Child Psychology and Psychiatry, 46(2), 211-222.

Sutton, S. K., \& Davidson, R. J. (1997). Prefrontal brain asymmetry: A biological substrate of the behavioral approach and inhibition systems. Psychological Science, 8(3), 204-210.

Symes, W., \& Humphrey, N. (2010). Peer-group indicators of social inclusion among pupils with autistic spectrum disorders (ASD) in mainstream secondary schools: A comparative study. School Psychology International, 31(5), 478-494.

Tantam, D. (2003). The challenge of adolescents and adults with Asperger syndrome. Child Adolescence and Psychiatric Clinics of North America, $12,143-163$.

Thompson, P., Giedd, J., Woods, R., MacDonald, D., Evans, A., \& Toga, A. (2000). Growth patterns in the developing brain detected by using continuum mechanical tensor maps. Nature, 404, 190-193.

Thurm, A., Bishop, S., \& Shumway, S. (2011). Developmental issues and milestones. In J. Matson \& P. Sturmey (Eds.), International handbook of autism and pervasive developmental disorders (pp. 159-173). New York, NY: Springer.

Tomarken, A. J., Davidson, R. J., Wheeler, R. E., \& Doss, R. C. (1992). Individual differences in anterior brain asymmetry and fundamental dimensions of emotion. Journal of Personality and Social Psychology, 62(4), 676.

Tse, J., Strulovitch, J., Tagalakis, V., Meng, L., \& Fombonne, E. (2007). Social skills training for adolescents with Asperger's syndrome and high functioning autism. Journal of Autism and Developmental Disorders, 37, 1960-1968.

Uchino, B. N., Cacioppo, J. T., \& Kiecolt-Glaser, J. K. (1996). The relationship between social support and physiological processes: A review with emphasis on underlying mechanisms and implications for health. Psychological Bulletin, 119(3), 488.

Varela, F., Lachaux, J., Rodriguez, E., \& Martinerie, J. (2001). The brain web: Phase synchronization and large-scale integration. Nature Reviews Neuroscience, 2, 229-239.

Vaughan Van Hecke, A., Meyer, A., Stevens, S., Dolan, B., Karst, J., Schohl, $\mathrm{K}$., et al. (2012). PEERS treatment leads to increased neural activity in adolescents with ASD. Poster presented at the 9th International Meeting for Autism Research (IMFAR), Toronto, Canada. 
NOT THE PUBLISHED VERSION; this is the author's final, peer-reviewed manuscript. The published version may be accessed by following the link in the citation at the bottom of the page.

Wan, C. Y., Marchina, S., Norton, A., \& Schlaug, G. (2012). Atypical hemispheric asymmetry in the arcuate fasciculus of completely nonverbal children with autism. Annals of the New York Academy of Sciences, 1252(1), 332-337.

White, S., Leonig, K., \& Scahill, L. (2007). Social skills development in children with autism spectrum disorders: A review of the intervention research. Journal of Autism and Developmental Disorders, 37, 18581868.

White, S. W., \& Roberson-Nay, R. (2009). Anxiety, social deficits, and loneliness in youth with autism spectrum disorders. Journal of Autism and Developmental Disorders, 39(7), 1006-1013.

Whitehouse, A. J., Durkin, K., Jaquet, E., \& Ziatas, K. (2009). Friendship, Ioneliness and depression in adolescents with Asperger's Syndrome. Journal of Adolescence, 32(2), 309-322.

Wing, L. (1981). Language, social, and cognitive impairments in autism and severe mental retardation. Journal of Autism and Developmental Disorders, 11, 31-44.

Yakovlev, P., \& Lecours, A. (1967). The myelogenetic cycles of regional maturation in the brain. In A. Minkowski (Ed.), Regional development of the brain in early life (pp. 3-70). Oxford: Blackwell Scientific. 